\title{
The digital leader: what one needs to master today's organisational challenges
}

\author{
Milan Frederik Klus ${ }^{1} \cdot$ Julia Müller ${ }^{2}$ (D)
}

Accepted: 25 March 2021 / Published online: 26 April 2021

(C) The Author(s) 2021

\begin{abstract}
Executives are increasingly facing various challenges associated with digitalisation, especially the simultaneous handling of many topics, loads of information flushing in via digital channels, rapid changes, and finding the right balance between the old and the new. Building on a growing body of research suggesting and systematising leadership skills, we conduct an online-survey with executives to investigate the connection between selected skills and the ability to cope with specific challenges. We find that a strong ability to think and act entrepreneurially, (self-)organisation and IT skills, a profound ability to motivate others, and a high degree of flexibility, commitment, and creativity are positively linked to the ability to cope with several digitalisation-related challenges. Surprisingly, being a strong team player does not seem to be necessarily advantageous. Moreover, many executives desire more calmness, which suggests that being able to decelerate is important in the digital age.
\end{abstract}

Keywords Digital leader $\cdot$ Digitalisation $\cdot$ Leadership skills $\cdot$ Survey $\cdot$ Traits

JEL classification M12 $\cdot \mathrm{M} 15 \cdot \mathrm{M} 51 \cdot \mathrm{M} 54 \cdot \mathrm{O} 32 \cdot \mathrm{O} 33$

\section{Introduction}

Work environments and occupations are undergoing significant changes, with progressive digitalisation playing a pivotal role. The internet, high-performance computing, and ubiquitous mobile technologies offer new opportunities to capture and analyse trends and behaviour (George et al. 2016) and to shape

Julia Müller

julia.mueller@uni-osnabrueck.de

Milan Frederik Klus

milan.klus@uni-muenster.de

1 Institute for Organisational Economics, University of Münster, Scharnhorststr. 100, 48151 Münster, Germany

2 University of Osnabrück, Rolandstr. 8, 49069 Osnabrück, Germany 
collaboration within and between organisations. The human resource management (HRM) of today's organisations is already infused with information technology (Bondarouk and Ruël 2009), with the driving factors being the spread of ever more sophisticated software for enterprise resource planning (ERP) and internetbased systems for the automation of activities and processes (Marler and Parry 2016). While many middle-skill jobs involve tasks that can be automated with the help of modern technologies today or in the near future (Autor 2015), even jobs with complex tasks and correspondingly high demands on the abilities of the job holder are affected by increasing technologisation. Executives and employees of contemporary organisations can communicate and interact via digital channels (Phelps 2014), can work remotely and according to flexible working time models (Tarafdar 2016), and have access to a wealth of data (Colbert et al. 2016).

Executives are increasingly facing the challenge of adequately incorporating new technological developments into their organisations while at the same time shaping the process of change in their own operations. According to Avolio and Kahai (2003), the changes in the work environment are driving executives to rethink their approaches and behaviour. In this context, particularly relevant questions include how to manage locally dispersed teams, how to handle different technology preferences, and how to design a functioning knowledge transfer (Gratton 2016). At the top management level, executives must rethink the design of the corporate strategy and business model and adapt it to modern requirements (El Sawy et al. 2016).

So far, however, many companies use digital technologies only to a limited extent (Colbert et al. 2016). In this context, executives play an essential role in implementing appropriate structures and processes as well as in encouraging employees to have a positive attitude towards digitalisation (Wipulanusat et al. 2017). Executives thus lay the foundation for digital transformation (Hunt 2015) while at the same time acting as role models and pioneers (Day et al. 2014). This leads to new challenges for executives-which can be managed only with proper leadership skills.

To describe leadership in an increasingly technology-infused work environment, the literature has already coined terms such as digital leadership (Ahlquist 2014; El Sawy et al. 2016; Sheninger 2019; Wilson 2004), e-leadership (Avolio et al. 2000; Avolio and Kahai 2003; Cascio and Shurygailo 2003) and e-HRM (Bondarouk and Ruël 2009; Marler and Parry 2016; Ruël et al. 2004, 2007; Strohmeier 2007). Furthermore, some contributions have addressed the identification and systematisation of relevant leadership skills in an increasingly digitalised work environment (Khan and Ahmad 2012; Klus and Müller 2020; Phelps 2014; Tarafdar 2016; Zeike et al. 2019). So far, however, researchers have not focussed on the relationship between selected leadership skills and the ability to cope with specific digitalisation-related challenges. We bridge this gap and address this question using a survey-study that is based on the current state of knowledge in the literature and provides new insights and contributions in two ways:

1. The questionnaire design allows us to empirically analyse the links between selected leadership skills and executives' abilities to cope with different digi- 
talisation-related challenges, also considering personal traits as well as relevant control variables (age, gender, management level, leadership experience, and number of supervised employees).

2. Through open questions, we generate new insights into leadership skills and personal traits which are particularly needed today; these insights partly confirm the findings from previous studies but also expand the current state of research.

The core contribution of this paper to the growing body of literature on digital leadership lies in contextualising leadership skills by clarifying their relevance in handling specific digitalisation-related challenges. We find that some skills are particularly helpful for managing several digital challenges, while others only seem helpful in relatively few occasions. We hope our results encourage scholars to elaborate on the context-specific view on digital leadership skills and help HR practitioners in personnel selection and development.

\section{Related literature and research focus}

To provide a suitable theoretical foundation for exploring the link between digitalisation-related challenges and the strength of particular skills and traits, we have divided this section into two subsections. Subsection 2.1 first provides insights into leadership challenges being discussed in the literature. Subsection 2.2 then presents insights into the current state of the literature on leadership skills. We present our research questions at appropriate points during the argumentation.

\subsection{Leadership challenges}

With regard to organisational challenges, key issues that arise include managing intergenerational teams (Gratton 2016), ensuring the adequate use of modern technologies, and establishing suitable boundaries between work and non-work contexts (Tarafdar 2016). The aspect of age is not only a challenge in terms of the composition of workforces or teams, but also for executives themselves. Although most young managers grew up with modern technologies and thus bring valuable know-how to companies, they are oftentimes perceived as less prototypical and are accorded a lower status by employees (Buengeler et al. 2016). On the other hand, technically apt executives have to reconcile employees with different degrees of technological aptitude, thereby focussing on those who tend to oppose the adaptation of new technology or lack knowledge (Dimitrov 2018). When managing digitalisation-induced change processes, executives have to strive for a balance between the old and the new and bring a sufficient number of employees on board (Colbert et al. 2016).

Having a multitude of (digital) communication channels and devices opens up opportunities for working in virtual teams and requires executives to lead a decentralised group, a form of leadership often referred to as remote leadership (Colbert et al. 2016; Kane et al. 2019). But, along with the rise of virtual teams, 
several issues have also been identified. Specifically, Hambley et al. (2007) found that while task performance does not differ between teams using different types of communication, team cohesion and interaction may be compromised in virtual teams using solely chat for interaction. Another issue regarding remote leadership pertains to individuals feeling isolated in their work, as face-to-face interactions are decreasing despite an increase in communication means (Pulley and Sessa 2001). This changing way of communicating seems to negatively affect the trustbuilding between leader and follower (Savolainen 2014). It is, therefore, the leaders' responsibility to actively form stable relationships in virtual teams to overcome these difficulties (Roy 2012).

Through the extensive use of mobile devices and email, executives and employees alike may experience work content encroaching on their personal life and, thereby, have heightened levels of stress (Barley et al. 2011; Schwarzmüller et al. 2018). This can be further aggravated for executives, as they encounter large amounts of information to sift through and must deal with an increasingly diverse range of topics (Schwarzmüller et al. 2018). Moreover, due to a business environment which is developing fast as a result of digitalisation, people's workloads are increasing and tasks must be fulfilled swiftly; the accelerating pace that accompanies digitalisation is a recurring theme in contemporary literature (Gordon and Martin 2019; Kane et al. 2019; Kohnke 2017; Schwarzmüller et al. 2018). For example, Kane et al. (2019) identify the speed of change as the single most defining characteristic of the digital business environment. The fast-paced digital era requires executives to make quick decisions that cannot be entirely habitual but need to include some element of innovation (Pulley and Sessa 2001). While the speed of change is challenging for executives themselves, they also need to address the fear and insecurity of their employees who may feel equally overwhelmed (Schwarzmüller et al. 2018).

Closely related to this is the need for personnel development. Digitalisation calls for employees with a digital skill set, and it is the executive's task to promote this (Kohnke 2017). Identifying the skills needed and spreading them within the workforce through adequate personnel development is a major new challenge for executives.

In addition, digitalisation exposes contemporary organisations to new risks, which executives have to cope with. In this context, IT security has been identified as a particularly pressing challenge for leaders (Kappelman et al. 2013). Moreover, the issue of data privacy has to be taken into account (Abowd et al. 2019; Zhang 2018), with the challenge of protecting data inside and outside of the organisation.

To expand the literature with novel insights into leadership challenges in the digital age, we first evaluate the relevance of different challenges discussed in recent studies and formulate the following research question:

RQ1.1: How relevant do executives rate digitalisation-related challenges which have been discussed in recent literature?

The digital age is characterised by a fast pace of change and a multitude of new issues (Kane et al. 2019; Kohnke 2017; Schwarzmüller et al. 2018). Therefore, we assume that previous studies have not yet fully covered the wide range of leadership challenges linked to digitalisation, and we thus examine the following research question: 
RQ1.2: In the context of an increasingly digitalised work environment, are there relevant leadership challenges that are not or only weakly anchored in the existing literature?

\subsection{Leadership skills}

To cope with organisational challenges, executives need an adequate skill set, which, according to early work by Katz (1974), should include technical skills, human skills and conceptual skills. Skills may also be different between novice leaders, intermediate leaders, and expert leaders, where, as pointed out by Lord and Hall (2005), leadership skills tend to be more self-centred in case of novice leaders and, with increasing experience, they more and more converge into an expert leader's ability to develop other employees (Lord and Hall 2005). These dimensions were used in a study by Klus and Müller (2020) to develop a conceptual framework systematising leadership skills, thereby also considering personal traits. Based on interviews with executives and an analysis of job advertisements for leadership positions, the study found that particularly relevant leadership skills in times of rapid technological change include the ability to communicate effectively via different channels, organisation skills, subject-specific knowledge (increasingly IT skills) and the ability to reflect on oneself (Klus and Müller 2020). In addition, key personal traits were also considered crucial, such as empathy and an open-mindedness towards the new.

Other literature also stresses the importance of technological affinity and computer knowledge for leaders. Executives need to stay informed about and understand new technologies (Sousa and Rocha 2019) and develop a range of technical skills to ultimately achieve some sort of digital literacy (Kane et al. 2019; Phelps 2014). As digitalisation comes along with a broad range of technological solutions and innovations, executives need to continuously update their knowledge (Schwarzmüller et al. 2018). This may result in an information overload, such that executives need to be able to use or leverage relevant technical knowledge in order to make decisions effectively (Sousa and Rocha 2019).

Apart from gaining IT knowledge themselves, executives also need to ensure that this knowledge gets integrated and spread within the organisation. For this, Phelps (2014) suggests that executives require organisation skills, especially when it comes to managing virtual teams. Furthermore, strong communication skills seem necessary for passing on IT knowledge and spreading the word regarding digitalisationinduced changes (Giles 2016; Iordanoglou 2018; Phelps 2014; Roy 2012; Sousa and Rocha 2019). As digitalisation alters the means of communication, communication skills need to be extended to a range of communication channels and platforms (Gordon and Martin 2019).

Motivational skills are highlighted on a number of occasions in contemporary leadership literature (Gordon and Martin 2019; Iordanoglou 2018; Schwarzmüller et al. 2018; Sousa and Rocha 2019). With regards to digitalisation, Osburg and Lohrmann (2017) indicate that the ability to motivate others could be relevant when encouraging employees in their acquisition of IT skills. To achieve this both at the company's own location and in globally dispersed (virtual) teams, 
foreign language skills (especially English) seem relevant (Klus and Müller 2020; Osburg and Lohrmann 2017; Schwarzmüller et al. 2018).

In addition to what skills are deemed to equip executives for the twenty-first century, the literature also highlights a range of desired personal traits. Most prevalent are traits associated with facilitating change, such as flexibility (Phelps 2014; Iordanoglou 2018) and the willingness to change (Sousa and Rocha 2019), which may require a certain degree of courage by the leader to overcome resisting forces inside the organisation (Crossan et al. 2017; Seijts and Gandz 2018). Furthermore, creativity allows executives to change their organisation in new ways and solve problems (Mumford et al. 2017; Sternberg 2017). In times of crisis, executives benefit from higher levels of empathy, as this allows them to better understand and consider their employees while maintaining a certain degree of goal orientation (Iordanoglou 2018).

Overall, the existing literature has concentrated particularly on identifying relevant skills and traits for executives on a more superordinate level, with digitalisation only gradually being taken into account. As far as we know, however, there is little empirical evidence to date of direct links between leadership skills/traits and executives' abilities to cope with specific digitalisation-related challenges. This is where the present study comes in and contextualises leadership skills by focussing on connections between high levels of coping competence for selected leadership challenges and executives' strengths of different skills and traits. Accordingly, we formulate the following research question:

RQ2.1: How is an executive's ability to cope with relevant digitalisationrelated leadership challenges associated with the strengths of their different skills and traits?

Although we refrain from formulating hypotheses due to the exploratory nature of this paper, we would like to formulate some a priori expectations regarding the link between some challenges and skills/traits based on the literature presented in this section. Accordingly, the research by Klus and Müller (2020) suggests that strong communication skills, organisation skills, and IT skills help executives in dealing with rapid technological change. Considering the work by Phelps (2014), we also suspect a positive correlation between organisation skills and the ability to manage virtual teams. Even if organisation skills represent a fundamentally relevant ability in the leadership context, it is reasonable to assume that decentralised management via virtual channels is particularly challenging. In line with Osburg and Lohrmann (2017), we expect motivational skills to be central in meeting the challenge of reducing IT aversion in the workforce and promoting a positive attitude towards technological innovation. With regard to personal traits, we expect flexibility and the will to change to be particularly helpful in managing rapid change (Phelps 2014; Iordanoglou 2018). Considering that standard solutions are giving way to innovative approaches in the digital age, we expect a high degree of creativity to be useful for developing novel solutions for emerging problems, which are likely to occur in, for example, remote leadership.

Again, as we suspect that the range of relevant skills and traits is not yet fully explored, we formulate our fourth research question: 
RQ2.2: Are there any leadership skills and personal traits gaining relevance in an increasingly digitalised work environment that are not well anchored in the existing literature?

\section{Methodology and data}

To investigate our research questions, we have designed a questionnaire for an online survey with executives (see Subsection 3.1). In Subsection 3.2 we describe our procedure for collecting the sample, which is described in Subsection 3.3.

\subsection{The questionnaire}

The questionnaire consists of two main parts, dealing with our research questions on managers' skills and the challenges they face, and an additional final part with demographic questions. The questionnaire includes statements that participants were asked to evaluate according to a 5-point scale of the Likert type (Likert 1974), as well as open questions, similar to a survey conducted by Creţu and Iova (2015). A Likert-type scale has already been successfully used for this purpose in several studies, e.g. by Guillén et al. (2015) and Mumford et al. (2007).

A short introductory page welcomed the participants, introduced them to the topic of the survey and ensured confidentiality.

\subsubsection{First part of the questionnaire: skills}

Executives were asked to evaluate the strength of given skills and traits in relation to their own person. The information was given on a 5-point Likert scale, which ranged from $0=$ weak to $4=$ strong. In addition, a response option "no information" was offered in order not to force an evaluation. All skills and traits were listed following a random order (different for each participant) to prevent biased results stemming from a fixed order.

Moreover, an open question was asked as to what other skills and traits the managers would like to have in order to cope with digitalisation-related challenges, which allowed us to cover further relevant skills.

\subsubsection{Second part of the questionnaire: challenges}

In the next part, the relevance of different challenges was queried using a 5-point Likert scale ranging from $0=$ irrelevant to $4=$ relevant. The selected challenges were chosen from academic studies already dealing with the digital age (see Sect. 2). To avoid that participants of the study might interpret the given challenges differently, we supplied a headline of each challenge together with a short definition in the questionnaire (see Table 4 in Appendix 1 for the exact wording of our explanations of the challenges). 
At the end of this part, an open question was asked about further digitalisationrelated challenges to allow for additional findings.

Furthermore, the respondents were asked to evaluate how easy it is for them to cope with the predefined challenges. For this, a 5-point Likert scale was used ranging from $0=$ hard to $4=$ easy.

\subsubsection{Third part of the questionnaire}

Finally, the concluding part of the questionnaire consisted of questions focussing on demographic and company-specific data (Guillén et al. 2015), comprising the respondents' gender, age, management level, leadership experience, number of supervised employees, and company size.

\subsubsection{Summary of the variables in the questionnaire}

In total, we consider 11 leadership challenges, 13 skills, and 10 personal traits, the selection of which results from a thorough analysis of the literature presented in Table 3 in the Appendix. Table 4 in the Appendix provides descriptions of the challenges and shows the average relevance they were given by the survey participants.

\subsection{Collection of the sample}

We focussed our study on industrial companies in northwest Germany, as this sector provides a fertile field for studying digitalisation-related phenomena, and a regional focus increases the comparability of the results. Before the survey period, we collected information about the target companies and their executives (company name, names of executives, position, telephone number, email address etc.) from the company websites. ${ }^{1}$ All companies were phoned and informed about the survey and its main focus before we sent them the link to the online survey to increase response-rates. $^{2}$ The link to the questionnaire was sent out from a university email address between the end of December 2018 and May 2019. In order to avoid biased responses, the survey was conducted anonymously.

\footnotetext{
${ }^{1}$ Using an online survey allowed for fast data collection, and, as is advantageous for all electronic questionnaires as compared to paper-based ones, the process of transforming responses into a machine-readable format occurred during collection, obviating the need for post-collection processing activities (Franklin and Walker 2003).

${ }^{2}$ At the beginning of our study, we emailed the survey link to 80 executives whose personal email addresses were publicly available (without phoning them in advance). However, due to a response rate below ten percent we decided to change our procedure.
} 


\subsection{Sample}

In total, we contacted 519 companies and received 148 completed questionnaires. ${ }^{3}$ Our empirical analysis is thus based on a final sample of 148 executives from predominantly medium-sized industrial companies in northwest Germany.

Of the 139 respondents who indicated their gender, $99(71.22 \%)$ were male and $40(28.78 \%)$ female. 140 executives answered the question about their age. The age category of 50-59 year olds was most strongly represented with 53 (37.86\%) executives, followed by 40 (28.57\%) 40-49 year olds and 35 (25\%) 30-39 year olds. Only $6(4.29 \%)$ of respondents fell into the $<59$ category and $5(3.57 \%)$ into the $<30$ category.

Of 140 executives who indicated their management level, 75 (53.57\%) were middle managers, followed by $38(27.14 \%)$ top managers, and 19 (13.57\%) who described their position as being in lower management. The remaining executives either did not provide any information or were unable to assign their position to a specific management level.

The number of supervised employees $(N=139)$ ranged from $<10$ to $>29$ individuals, with $68(48.92 \%)$ of the surveyed executives being responsible for fewer than 10 employees. However, 31 (22.30\%) executives responded that they lead more than 29 employees. The categories between (executives with $>10$ supervised employees but $<29)$ were somewhat less represented, with $26(18.71 \%)$ executives being responsible for 10-19 employees and 12 executives (8.63\%) for 20-29 employees.

An overview of the summary statistics of our data can be found in Table 1. Descriptions of the challenges considered in our study are presented in Table 4 in the Appendix.

\subsection{Data analysis}

In order to evaluate the free response fields of the survey, we compared the answers, which often consisted of only one or a few words. Similar to the Gioia method (Gioia et al. 2013), we grouped the answers into second order themes if possible and counted the frequency of naming as an indicator of their relevance (see Figs. 1, 2). We decided not to build overarching dimensions of the second order themes, since their number is relatively small and we did not want to provoke any loss of information. Using this approach, 54 of 67 statements regarding further relevant digitalisation-related challenges could be compressed into 13 overarching themes (see Fig. 1). The remaining 13 statements showed no similarities with each other or with the other statements and were therefore not considered further in the analysis. With regard to (further) leadership skills that the survey participants would like to have in the context of increasing digitalisation, 59 of 82 statements could be condensed into

\footnotetext{
3 In total, 156 participants completed the questionnaire. We used the first eight participants to inspect the questionnaire once more. We asked for feedback on the feasibility and understandability of the questionnaire and the time required to complete it. This test phase led only to very minor modifications of the questionnaire.
} 


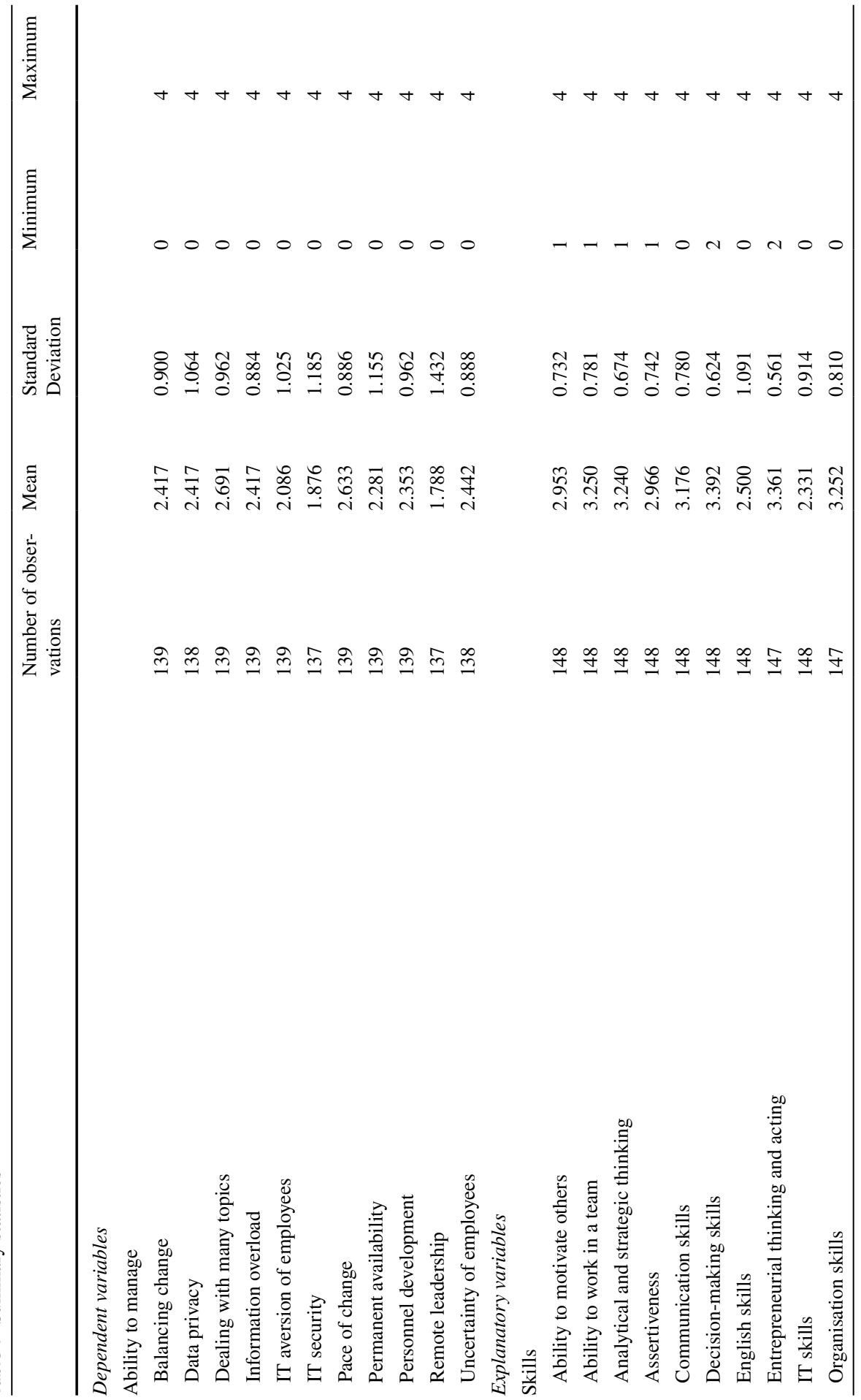




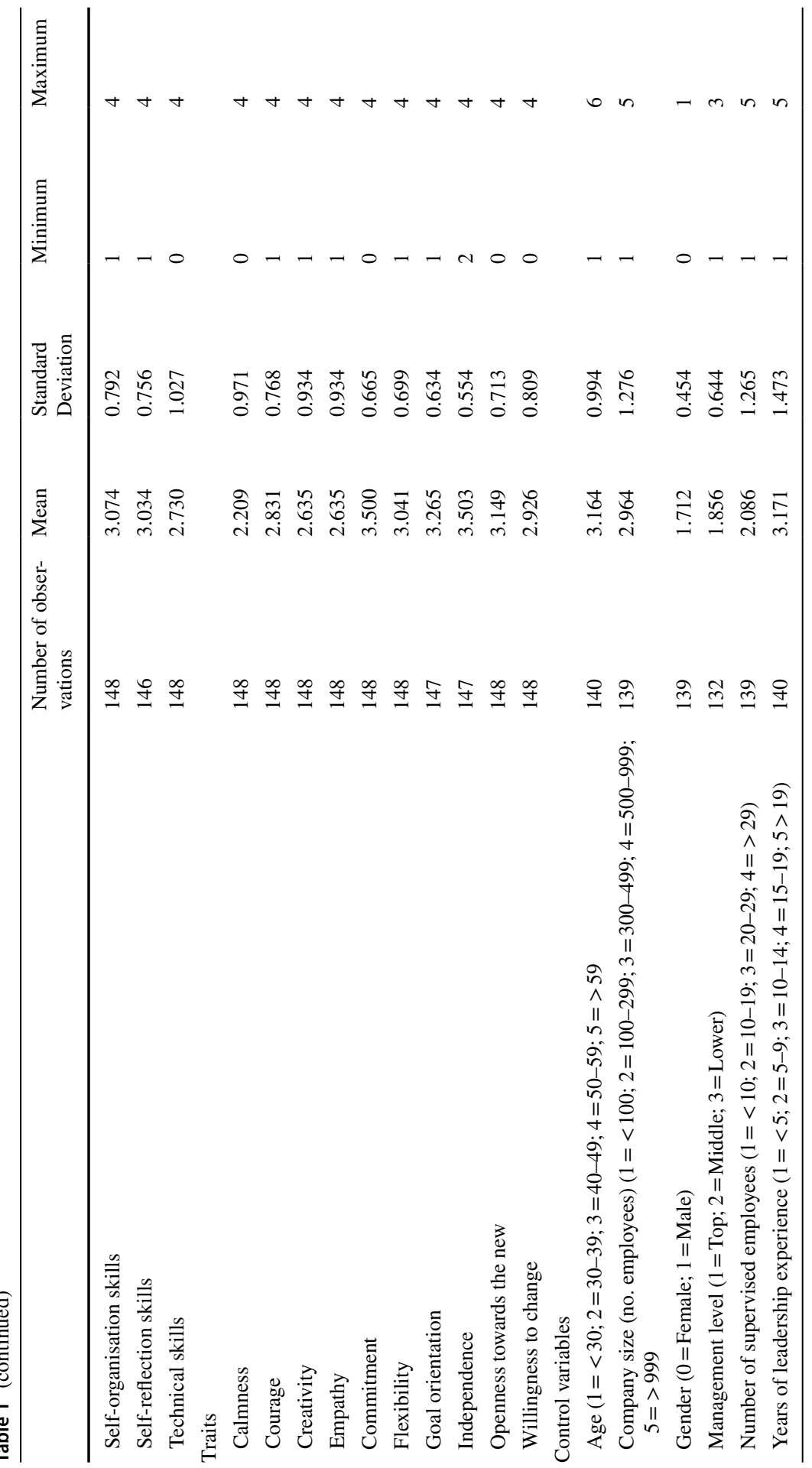




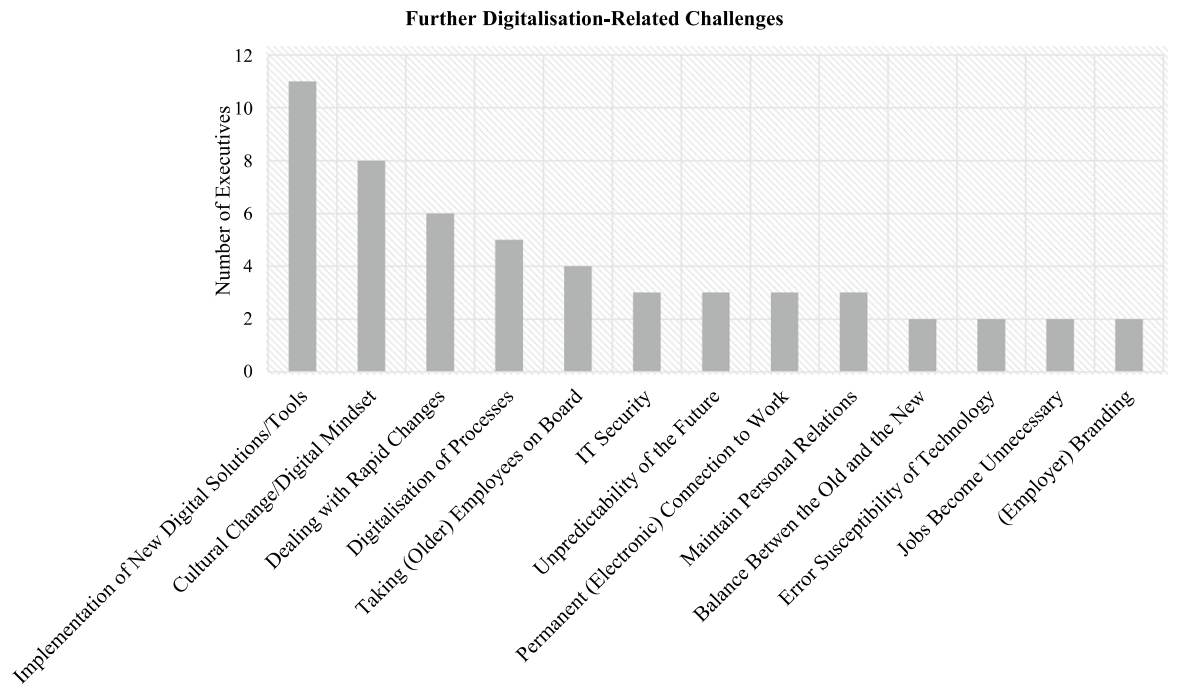

Fig. 1 (Further) Digitalisation-related challenges

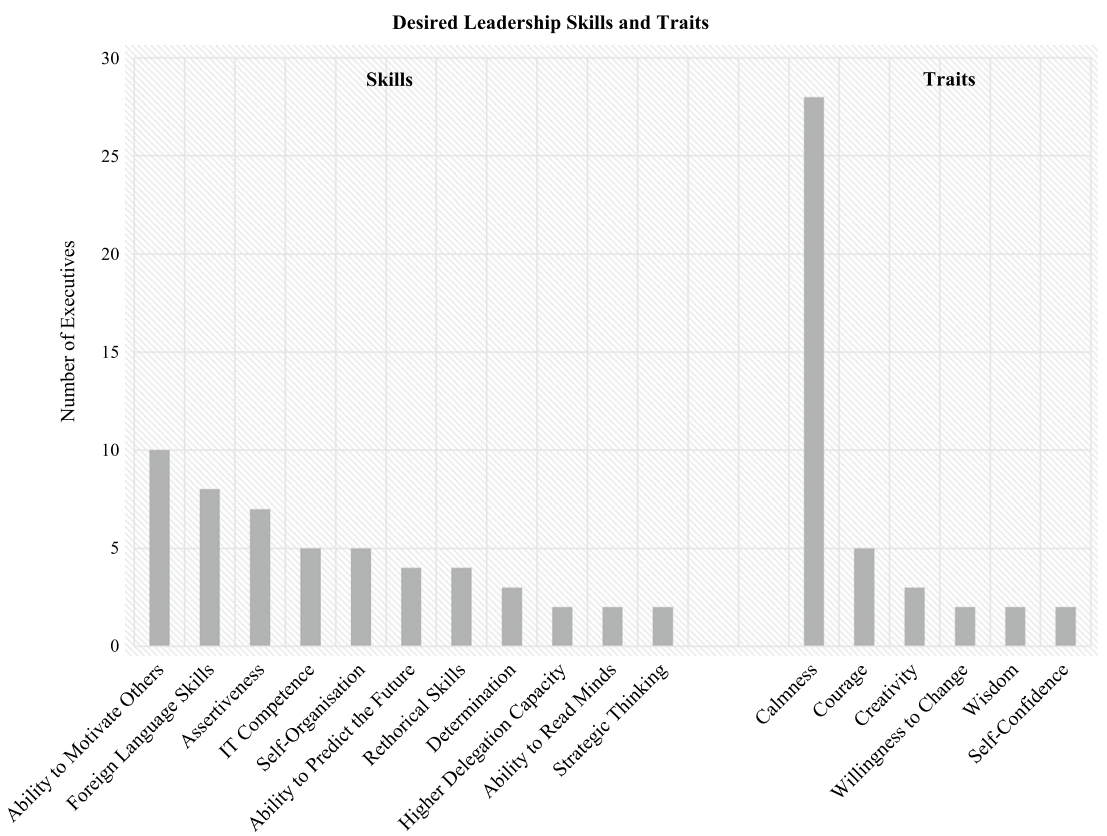

Fig. 2 Desired skills and traits

11 overarching themes (see Fig. 2). In addition, 42 of 52 statements regarding further relevant traits could be summarised in six superordinate themes, also depicted in Fig. 2. 
To investigate links between executives' strengths of different skills/traits and their ability to cope with digitalisation-related challenges, we applied ordered probit regressions. For each model, we used the ability to cope with a specific challenge as the ordinal dependent variable and the strength of skills and traits as the explanatory variables. We controlled for the individual-specific parameters age, gender, management level, leadership experience, and number of supervised employees. We additionally controlled for the perceived relevance of the challenges, as there might be a correlation between the ability to cope with a challenge and its perceived relevance. To test whether two or more explanatory variables are highly correlated to each other, we used a metric know as variance inflation factor (VIF), the results of which are presented in Subsection 4.2.

\section{Results}

We present our results in two subsections. In the first subsection, we start with the assessment and identification of digitalisation-related leadership challenges (RQ 1.1; RQ 1.2) and skills/traits (RQ 2.2). In the second subsection, we present the results of the regression analysis to identify connections between the strength of specific skills/traits and the ability to cope with different challenges (RQ 2.1).

\subsection{Assessment and identification of digitalisation-related challenges, skills, and traits}

To ensure that the challenges selected for the questionnaire were relevant to the executives surveyed, participants were asked to assess the relevance of the predefined challenges (see fifth table for the descriptions) on a 5-point Likert scale ranging from $0=$ irrelevant to $4=$ relevant. Accordingly, the challenges of dealing with many topics, information overload, pace of change, and balancing change were ranked as the most relevant (in descending order), with all having a mean value above 3.0. The list continued with personnel development, uncertainty of employees, data privacy, permanent availability, IT security, and employees' aversion to IT (mean $<3.0$ and $>2.0$ ). Remote leadership was the lowest ranked, with a mean value of 1.90. Overall, this shows that none of the selected challenges were classified as irrelevant, which legitimises their use for further analysis.

In response to the open question as to which (further) digitisation-related challenges the executives considered relevant, they mentioned (in descending order) the implementation of new digital solutions and tools, the cultural change towards a digital mindset, the handling of rapid changes, the digitisation of processes and the task of taking the older workforce with them into the digital age (see Fig. 1). Other issues recurrently mentioned in the context of digitisation-related challenges included IT security, the uncertainty of the future, the permanent (electronic) connection to work, and maintaining personal relationships.

An analysis of the self-assessed skills and traits of the survey participants shows that female participants rated their ability to (self-)organise higher than male 
participants. Regardless of gender, organisation skills were weakest among the under-30 s, which indicates a high relevance of experience in this context. IT competence and technical understanding was higher among the male executives surveyed.

With an open question, we collected skills and traits that executives would like to have or to have strengthened. Several respondents expressed the wish to be able to motivate others better and to have better foreign language skills (especially English), followed by better assertiveness, higher IT competence and an increased ability to organise themselves (see Fig. 2). Interestingly, the desire to predict the future was also expressed several times, indicating the difficulty of making informed strategic decisions in times of rapid change.

A surprising result is the high number of executives who wished to have more calmness (see Fig. 2). The personal trait calmness is not well anchored in the leadership literature so far, which could indicate that calmness is gaining relevance in times of rapid technological progress. In addition, some leaders wished to strengthen their courage, creativity and willingness to change, wisdom, and self-confidence.

\subsection{Regression analysis}

A central objective of the study was to answer the question of which skills and traits are significantly related to an executive's ability to cope with specific digitalisationrelated challenges (RQ 2.1). To analyse this we used ordered probit regressions, the main results of which are summarised in Table 2 and detailed in Tables 5 and 6in the Appendix. The challenges in Table 2 are sorted in descending order according to their assessed relevance. Taking into account all explanatory variables, the mean variance inflation factor (VIF) is 1.76 , indicating that the models used do not suffer from multicollinearity.

Overall, the self-evaluation of the ability to cope with specific digitalisationrelated challenges shows that the executives surveyed found it comparatively difficult to deal with the issue of remote leadership, i.e., leading locally or even globally distributed teams. The coping competence around the topic of IT security was also rated relatively low, followed by competence surrounding employees' aversion to IT.

On the skills side, the results of the regression analysis show that the ability to organise oneself and one's organisational environment as well as IT skills, the ability to motivate others, and entrepreneurial thinking and acting are significantly positively associated with more than one perceived coping competence, suggesting a particularly high relevance of these skills. The same applies to the personal traits of commitment, flexibility and creativity. Interestingly, we find several significant negative correlations between the ability to work in a team as well as analytical and strategic thinking and the perceived ability to cope with different challenges- this finding is reflected on more deeply in the discussion.

Our results show that the ability to deal with many topics, to cope with an information overload, and to manage fast-paced change is positively associated with the personal trait of flexibility. However, being a strong team player does not seem to help master the three challenges considered here, as indicated by significantly negative correlations. 


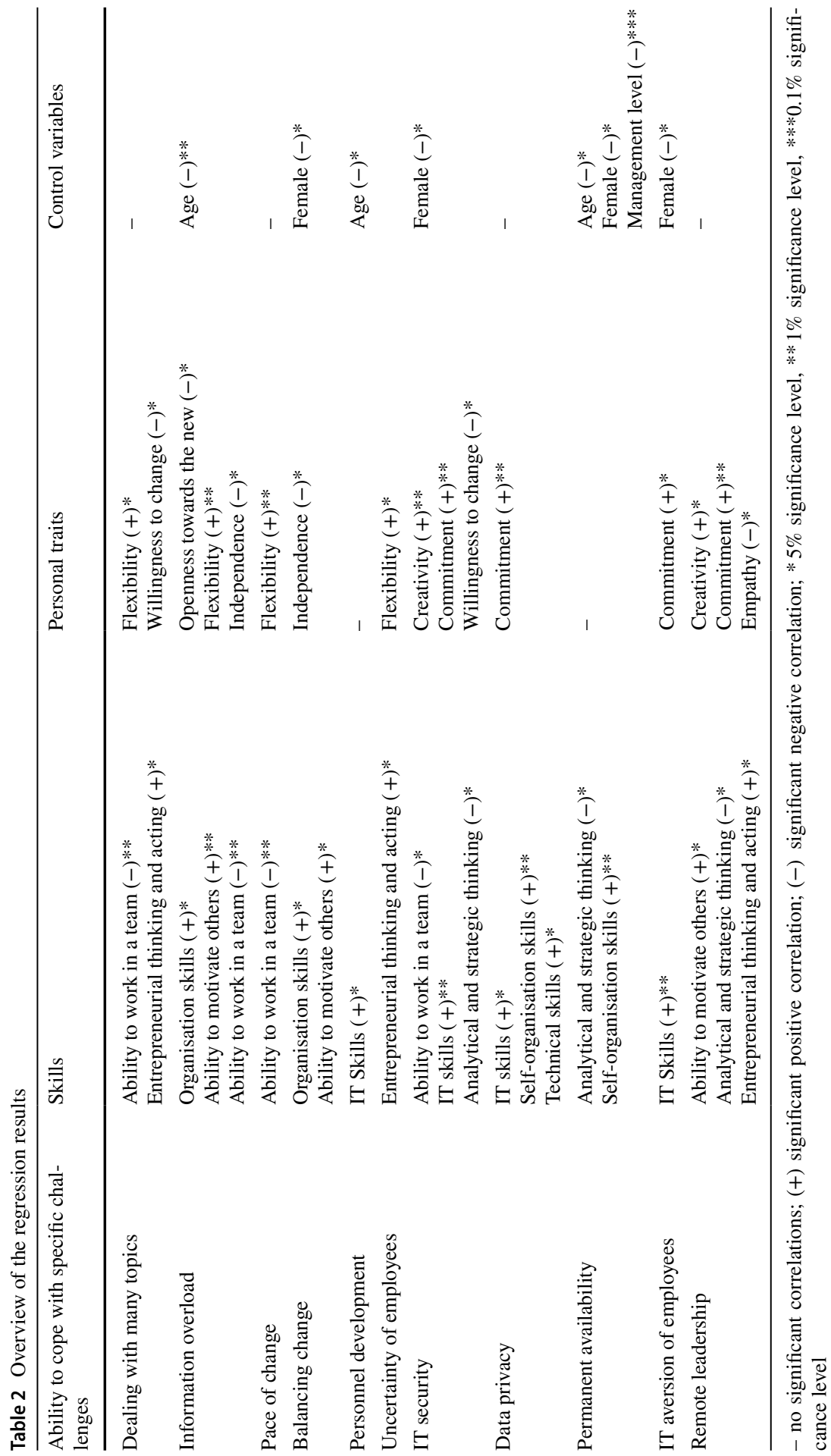


With regard to the ability to deal with many topics, we find a significantly positive connection with the ability to think and act entrepreneurially and a significantly negative link to executives' willingness to change. The ability to cope with an information overload is significantly positively correlated with organisation skills and the ability to motivate others. Interestingly, our results further show a negative link between the ability to cope with an information overload and independence as well as an open-minded attitude towards the new. Moreover, as indicated by the significant negative coefficient of the control variable age, younger executives feel more able to cope with an information overload and ensuring adequate personnel development compared to their older colleagues.

While independence is negatively associated with the ability to find the right balance in change processes, this ability is facilitated by strong organisation skills and the ability to motivate others. Being able to motivate others seems also advantageous when it comes to mastering remote leadership, thus managing employees working from different geographical locations. In addition, entrepreneurial thinking and acting as well as commitment and creativity appear to help leaders handling remote leadership. However, analytical and strategic thinking is significantly negatively correlated with remote leadership, as well as with the ability to master challenges around IT security and being permanently available. The results further indicate a negative correlation between empathy and the ability to manage remote leadership.

Profound IT skills seem to be beneficial to executives in more than one challenge, namely the design of demand-oriented personnel development, dealing with issues of IT security and data privacy, and dealing with employees' aversion to IT. Our results further indicate that self-organisation skills are positively linked to the ability to manage data privacy and being permanently available. Regarding the challenge of permanent availability, we further find a significantly negative connection to the age and management level $(1=$ top management, $2=$ middle management, $3=$ lower management), with the latter suggesting that older executives and those working in lower and middle management positions find it more difficult to deal with this challenge compared to younger and top management executives. Younger managers also seem to find it easier to deal with the challenge of appropriate personnel development, as indicated by a significantly negative coefficient of the variable age.

Finally, we find a significantly positive correlation between commitment and the ability to deal with the issues of IT security, data privacy, and an IT aversion of employees, with IT security also showing a significantly positive link to the personal trait of creativity. However, being a team player, as well as having a strong ability to think analytically and strategically and having a high willingness to change does not seem to be beneficial when it comes to managing IT security, as indicated by significantly negative correlations.

\section{Discussion}

The discussion section is subdivided into three subsections, starting with a discussion of our empirical findings, followed by implications and limitations of the study. 


\subsection{Discussion of the empirical findings}

One might wonder why a renewed exploration of leadership skills and traits is relevant, given that these have long been the subject of academic research. A major reason is that an increasingly digitalised work environment poses new challenges to executives, making it reasonable to ask what it takes to cope with these challenges in order to successfully navigate today's organisations through the digital age. Pulley and Sessa (2001) argue that fundamental skills such as communication skills and the ability to motivate others, which are traditionally associated with leadership, remain as important as ever, whereby adapting traditional leadership skills to a technologically-mediated work environment adds an unprecedented degree of complexity. With this study, we confirm this argument empirically. We further argue that, in addition to changes within existing constructs, selected skills and traits, such as IT competencies and calmness, are gaining relevance and thus require in-depth analysis.

\subsubsection{Leadership skills}

Our questionnaire included the open question of what skills executives would like to have our to have strengthened. In response to this question, leading the list was a strong ability to motivate others. This is interesting, as this ability is traditionally linked to leadership (e.g., Gordon and Martin 2019; Iordanoglou 2018; Schwarzmüller et al. 2018; Sousa and Rocha 2019) and is therefore not a specific phenomenon of the digital age. It is consequently worth investigating in which contexts the ability to motivate others is particularly relevant today, as will be taken up later in this discussion. Second most frequently mentioned were foreign language skills (especially English), which indicates that executives increasingly need to be able to act internationally and coordinate activities with foreign business partners or geographically dispersed teams. An interesting finding is the desired ability to predict the future. Although Big Data increasingly helps to calculate the probability of future events (George et al. 2014), the desire for more predictability is an expression of a high degree of uncertainty - a typical characteristic of the digital age.

With regard to personal traits, by far the most exiting result is the frequently named desire for calmness, which far surpasses all other traits mentioned in response to the open question in our questionnaire. Ruderman et al. (2001) found that a leader's reaction under pressure or to challenges in terms of calmness largely determines how their leadership is perceived. With some exceptions, such as Seijts and Gandz (2018) as well as Cable and Judge (2003), the trait of calmness is not yet strongly anchored in the leadership literature and thus seems to build a relevant extension.

\subsubsection{Leadership challenges}

Our results show that particularly challenging to executives is the sheer amount of information and issues they must deal with. In this context, Schwarzmüller et al. (2018) emphasise electronic communication channels as the cause through which large amounts of information can be transmitted within the shortest 
possible time. Based on our results, strong organisation skills are significantly positively correlated with a high perceived ability to cope with information overload. Since it is almost impossible to prevent executives from encountering an increased amount of information via various (digital) channels, it is important to adequately organise the processing of information and distribute these tasks among a motivated workforce.

The next relevant challenges revolve around the topic of change, essentially regarding the high speed of change and finding a balance in change processes. Our results suggest that finding a balance in change processes is positively associated with strong organisation skills and the ability to motivate others, suggesting that resilient structures are important, and these must be supported not only by executives alone but by a motivated workforce. In accordance with this argumentation, we find that balancing change is significantly negatively associated with the personal trait of independence, indicating that a "lone fighter" nature seems to be less beneficial in facing this challenge than feeling connected to and dependent on one's organisation. Here, the challenge of finding a balance in change processes differs quite clearly from the challenge of mastering rapid change, which shows a negative connection to a pronounced ability to work in a team. In situations where it is a matter of making quick decisions, a "lone fighter" nature seems to be advantageous, similar to when handling a lot of information and topics. In addition, our results show a positive correlation between the ability to master rapid change and the personal trait of flexibility (see also Phelps 2014; Iordanoglou 2018), indicating that executives need to be able to react to different requirements quickly.

The challenge that was ranked as least relevant compared to the other predefined challenges relates to dealing with remote leadership. One possible explanation for the relatively low relevance could be that decentralised work has not yet been implemented in the majority of companies included in our analysis and is, therefore, only gradually gaining relevance. While this conclusion is based on assumptions, our results indicate that being particularly good at dealing with remote leadership is positively associated with committed and motivated executives with a strong ability to think and act entrepreneurially and a profound ability to motivate others. As digitalisation progresses, an increasing number of employees can do some or all of their work at a home office or even from any location. In such a situation, managing teams in which members work from different locations will require executives to rethink their leadership approaches, not least because they will have fewer opportunities to interact face-to-face with employees (Pulley and Sessa 2001). Having fewer opportunities for direct interaction may explain why strong team players find it particularly difficult to master remote leadership. One reason for the positive correlation between the ability to manage remote leadership and commitment as well as creativity might be that a high level of commitment is conducive or even necessary for enabling goal-oriented collaboration between locally dispersed employees and teams, where the ability to develop creative solutions offers an advantage over standard approaches. 


\subsubsection{Relevant skills and traits for dealing with leadership challenges}

In the previous two subsections, we discussed our results on leadership skills and challenges for leaders in isolation. Now, we turn to the core results of our study concerning the connection between these two topics, namely which skills and traits of leaders are relevant in managing the challenges they face.

Here, an interesting result concerns the significantly negative correlation between a high openness towards the new and the ability to cope with a high volume of information. One possible explanation is that executives must filter the information they receive in order not to overstrain their employees. Executives with a comparatively lower openness towards the new may have an advantage in the process of selecting relevant information. At the same time, however, flexibility is significantly positively associated with a high ability to cope with a high volume of information, indicating that some degree of agility in dealing with the information is conducive.

A seemingly equal counterintuitive finding relates to the ability to handle many topics. We find that this ability is positively associated with flexibility, while it is negatively associated with a willingness to change. This, too, supports the abovementioned explanation that a certain steadfastness can support the handling of many topics and information. This exemplifies what Pulley and Sessa (2001) describe as a dilemma of keeping focus during times of constant change, which is inherent to the digital age. It is therefore not necessarily a contradiction that while flexibility is positively associated with the ability to cope with different challenges, we find that a willingness to change is simultaneously negatively associated with being able to handle a multitude of topics. A high willingness to change could go along with a lack of direction, which impedes a leader's ability to multitask. Instead, having a strong ability to think and act entrepreneurially seems to help when tackling a multitude of topics, indicating that approaching many topics with a company perspective helps in the process of filtering and prioritising.

We find that being a strong team player does not necessarily help when it comes to dealing with many topics and high amounts information, as indicated by significant negative correlations. Dealing with many topics and excessive information probably requires quick decisions without many interfaces for coordination, which is easier for more self-determined executives.

Self-organisation skills are also significantly positively associated with the ability to manage the issue of being permanently available. Executives and oftentimes their employees are theoretically connected to work around the clock through mobile technology, which can negatively impact work-life-balance (Barley et al. 2011). In addition, given the multitude of communication channels available, networking within organisations is also increasing. A distinct ability to organise oneself seems to be useful for bringing one's own accessibility into a manageable level, for example by separating times for private and professional activities. Furthermore, our results indicate that middle and lower management executives find it more difficult to deal with the issue of permanent availability than top management executives. One explanation is that middle and lower management executives are closer to the workforce and act as contact persons for problems and questions that arise in everyday working life, while the top management's focus is on more long-term and less 
acute strategic issues. Also, older executives seem to find it more challenging than their younger peers to deal with the issue of being permanently available, which is interesting, as younger employees are less likely to hold top management positions. Even more surprising is the significantly negative correlation between analytical and strategic thinking and the ability to deal with being permanently available. One might have expected that analytical and strategic thinking helps in finding a way to establish a balanced accessibility. Maybe the opposite is true, for example because analytical and strategic thinking leads executives to consider incoming information and requests in more detail. A more context-specific view is needed to make reasonable assumptions about why profound English skills are significantly positively related to managing permanent availability. Assuming that more and more correspondence takes place in English (Klus and Müller 2020; Osburg and Lohrmann 2017; Schwarzmüller et al. 2018), it could be assumed that executives with strong English skills need to spend less time and energy on communication than their colleagues with weaker English skills, who have to overcome language barriers in addition to managing the content. However, a more in-depth analysis based on contextspecific data is needed to draw meaningful conclusions.

Regarding all the results discussed so far, it should be emphasised that they relate only to analysing the connection between the perceived ability to cope with selected challenges and a self-evaluation of specific skills and traits. In other contexts, a high ability to work in a team (Iordanoglou 2018), a high willingness to change (Sousa and Rocha 2019), and other skills and traits that here are negatively related to coping with certain challenges can be very useful.

However, the ability to work in a team is conspicuous in the context of our study, as it is significantly negatively associated with several coping competences. Maccoby (2000) points out the paradox that despite the widespread call for teamwork skills amongst leaders, many contemporary leaders fall into the category of narcissistic leaders who might express that they enjoy working in a team but truly prefer not to: "Indeed, perhaps one of the greatest paradoxes in this age of teamwork and partnering is that the best corporate leader in the contemporary world is the type of person who is emotionally isolated" (Maccoby 2000, p. 5). Based on the results of a meta-analysis, Grijalva et al. (2015) suggest that narcissism is positively associated with leadership emergence. While we do not suggest that executives in our sample are in fact narcissistic leaders, the work of Maccoby (2000) shows that not all leaders would deem the skill of being able to work in a team as beneficial under all circumstances. Even if our interpretation of the results based on the available data is not yet commonly agreed upon, it is at least apparent that a pronounced ability to work in a team is not necessarily an advantage.

Our results show that IT skills are positively associated with more than one coping competence. Leaders can actively use technology to increase their presence or interact with employees only if they possess the computer knowledge to do so (Phelps 2014). In this context, Kitchin (2014) emphasises that while Big Data and new methods of data analysis make it possible to answer new questions in new ways, it is challenging to develop the skills needed to analyse the data appropriately and make sense of it. Many companies have started to use more and more data (George et al. 2014), meaning that given the plethora of technological solutions, leaders 
should at least have a good overview of different technologies and digital solutions (Sousa and Rocha 2019). This equips them with a toolkit from which they can choose an appropriate tool on a case by case basis and it also allows them to assess which IT skills are advantageous for building within their employees. The fact that IT skills are positively associated with the ability to ensure needs-oriented personnel development further corroborate that IT skills play an important role in introducing employees to modern technologies and preparing them for work in increasingly digitalised work environments. The significant positive association between IT skills and an executive's ability to deal with employees' aversion to IT further indicates that IT-savvy executives find it easier to create an open-minded attitude towards new technologies in the workforce. Colbert et al. (2016) confirm that sound knowledge of IT systems and how to operate them is crucial for effectively harnessing technology and overcoming reservations to doing so.

In addition, we find a significantly positive connection between IT skills (Klus and Müller 2020) and an executive's ability to cope with the issues of IT security and data privacy, indicating that a profound understanding of IT helps executives assess different measures of coping with related threats. Interestingly, creativity seems to be even more advantageous in this context than analytical and strategic thinking, probably because in many cases relatively little data and few precedents are available. Coping with IT security issues becomes even more difficult when rapid changes occur, which might explain that a high willingness to change is significantly negatively correlated with the ability to manage IT security. Furthermore, commitment seems to be relevant for handling both IT security as well as data privacy, whereby we additionally find a significantly positive connection between the ability to manage data privacy and technical skills as well as self-organisation skills. The significant positive coefficient associated with self-organisation might indicate that data privacy is more within one's own sphere of influence than the topic if IT security. Accordingly, a strong ability to organise oneself (Phelps 2014) could help executives adequately handle sensitive data and help maintain an overview.

\subsection{Implications}

Based on our results, we can formulate implications at the company level and with regard to the individual development of executives.

Companies should take into account that the selection and development of executives is central to the management of digital change, in addition to or as a part of a suitable business strategy. When hiring new executives, particular attention should be paid to ensuring that they have strong (self-)organisation and IT skills, a strong ability to motivate others, and a profound ability to think and act entrepreneurially.

In addition, executives should bring personal traits such as commitment, creativity, and flexibility, whereas a high willingness to change and open-mindedness towards the new seem not particularly helpful for successfully dealing with selected digitalisation-related challenges. A context-specific view is central here, as a high willingness to change and openness to new ideas might be helpful in other situations, for example in corporate strategy issues. With regard to the challenges 
considered in this study, however, executives should offer a certain amount of steadfastness in order to keep the organisation on course and not overburden it with too many changes. This relates well to one's ability to find the right balance in change processes, which was considered relevant by the survey participants. Based on our results, creativity can help executives deal with relevant challenges, making it an important personal trait as well.

On the skill side, we primarily recommend applying demand-oriented training measures in the areas of (self-)organisation and IT competences and management trainings on how to motivate others. In addition, we recommend responding to the desires stated by many executives for improving foreign language skills (especially English) and for displaying more assertiveness and stronger rhetorical skills with different training formats. With regard to personal traits, the wish of many executives for more calmness should be taken seriously, even if this falls into the category of personal traits and is therefore difficult to train. Nevertheless, offering various ways to promote relaxation, such as yoga classes, relaxation rooms, and massages, can be considered, as can psychological coaching on how to deal with stress.

However, many of institutions still rely on traditional methods such as face-toface education (Phelps 2014) and focus on the development of individual leaders. Thus, leadership education takes place in an isolated environment. However, leadership development requires the involvement of multiple individuals because leaders deal with employees and stakeholders on a daily basis (Day et al. 2014). The development of leadership skills involves considering cognitive, social, and behavioural skills, meaning that only focussing on behavioural styles is insufficient (Lord and Hall 2005). Accordingly, it is crucial that not only practicing leaders become aware of the leadership skills needed today but also that educational institutions do so, as these institutions provide an important foundation for the development of future leaders.

Overall, we recommend that the challenges discussed in this paper are first reflected upon in the respective company-specific context and then that companies identify their needs on this basis and define individualised measures for hiring and developing executives.

\subsection{Limitations}

The study has some limitations which must be considered in the interpretation of the results and should be addressed in future research.

First, the study is essentially based on an online survey answered by 148 executives. The sample size is appropriate for an explorative study aiming at generating initial insights, but it is too small to claim generalisability. In this context, our focus on medium-sized industrial companies in the northwest Germany should also be taken into account, which does allow a relatively high consistency of the sample and thus a high comparability of the answers but simultaneously limits the generalisability of the findings. Accordingly, larger studies considering other regions and further industries are needed to validate the results. 
A further limitation concerns the measurement of the skills, traits, and coping competences, as these were based on self-assessments of the survey participants. Accordingly, an incorrect assessment by the respondents could lead to distortions of the results. In order to counteract this as best as possible, the survey was conducted anonymously and the executives always had the option of choosing "no answer" if they could not or did not want to provide an answer. Moreover, a more precise measurement of the explanatory variables could have been achieved by querying their individual items instead of using single-item scales. This must be taken into account in addition to the problems of self-evaluation when interpreting the results. As described in Sect. 3, we have at least integrated explanations of the challenges in the questionnaire in order to ensure uniform interpretation.

On a more general level, it should be noted that identifying the effect of individual skills and traits in a complex structure of indigenous and exogenous factors is very difficult and prone to error. Even though correlational theorizing is still predominant in the field of management and this paper thus follows an established standard, more precise approaches are discussed and proposed in the more recent literature (e.g., Furnari et al. 2020).

\section{Conclusion}

What skills and personal traits does a digital leader need to successfully master digitalisation-related challenges in contemporary organisations? In this paper, we addressed this research question using an online-survey with executives. Exceeding existing research on leadership skills and challenges, we focus on the connection between selected skills/traits needed in the digital age and specific challenges.

Our results reveal that executives find particularly challenging the amount of information and topics they must deal with, followed by challenges that revolve around the topic of (fast-paced) change. Interestingly, the challenge of mastering remote leadership was classified as the least relevant of the predefined challenges executives considered. With an open question and using the Gioia method, we were then able to identify other challenges mentioned by executives: the two most frequently named were the implementation of new digital solutions/tools and a cultural shift towards a digital mindset, followed by dealing with rapid changes, which was also included in the original list of predefined challenges. Creating a digital mindset and mastering rapid changes produce considerable tension, as cultural changes require a lot of time, and time is scarce in the digital age.

Regarding desired skills or traits, several executives mentioned that they wish to be able to predict the future, which coincides with the challenge of the unpredictability of the future. Another particularly striking finding in the context of (further) desired skills and traits, however, was the executives' desire for more calmness. As the construct of calmness is not yet strongly anchored in the existing leadership literature, it should be examined in greater depth in the future.

The results of our regression analysis show that a strong ability to organise oneself and one's environment are positively associated with multiple coping competences, as well as the ability to motivate others and the ability to think and act 
entrepreneurially. While organisation skills are positively associated with the ability to master an information overload and to find the right balance in change processes, a pronounced ability to self-organise is significantly positively correlated with managing the issues of being permanently available and data privacy. Moreover, another skill that is positively correlated with the ability to cope with the challenge of data privacy is IT skills, which are also positively associated with challenges related to managing IT security and employees' aversion to IT. Also from the regression analysis, one surprising result is the negative connection between a strong ability to work in a team and several coping competences, indicating that a good digital leader does not necessarily have to be a strong team player, at least with regard to selected challenges considered in this study. With regard to personal traits, executives in contemporary organisations seem to benefit from a high level of flexibility, commitment, and creativity, as these traits are significantly positively correlated with the ability to cope with various digitalisation-related challenges.

Our results contribute to the literature in two ways: first, our findings help to evaluate leadership skills, traits, and challenges discussed in the existing literature against the background of an increasingly digitalised work environment. In addition, using open-ended questions, we pinpoint new aspects that are not yet strongly anchored in the literature, highlighting new research areas to be explored in the future. Second, we identify connections between relevant skills/traits and executives' abilities to cope with specific digitalisation-related challenges, which can be used to derive implications for a future-oriented human resource management.

\section{Appendix 1}

See Tables 3 and 4 .

Table 3 Literature review for survey items

\begin{tabular}{lc}
\hline Skills; traits; challenges & Referring literature \\
\hline $\begin{array}{l}\text { Skills } \\
\text { Ability to motivate others }\end{array}$ & $\begin{array}{c}\text { Gordon and Martin (2019), Iordanoglou (2018), Klus and Müller } \\
\text { (2020), Schwarzmüller et al. (2018), Sousa and Rocha (2019) }\end{array}$ \\
Ability to work in a team & Iordanoglou (2018), Klus and Müller (2020), Nurmi (1996), \\
& Phelps (2014) \\
Analytical and strategic thinking & Haycock et al. (2012), Iordanoglou (2018), Klus and Müller \\
& $(2020)$ \\
Assertiveness & Ames (2009), Ames and Flynn (2007), Bacon and Severson \\
& (1986), Santora (2007) \\
Communication skills & Giles (2016), Gordon and Martin (2019), Iordanoglou (2018), \\
& Khan and Ahmad (2012), Klus and Müller (2020), Mumford \\
& et al. (2007), Phelps (2014), Sousa and Rocha (2019) \\
\hline
\end{tabular}


Table 3 (continued)

\begin{tabular}{|c|c|}
\hline Skills; traits; challenges & Referring literature \\
\hline Decision-making skills & Sousa and Rocha (2019) \\
\hline Entrepreneurial thinking and acting & $\begin{array}{l}\text { Klus and Müller (2020), Kuratko and Hornsby (1999), Sousa and } \\
\text { Rocha (2019) }\end{array}$ \\
\hline English skills & Klus and Müller (2020), Schwarzmüller et al. (2018) \\
\hline IT skills & $\begin{array}{l}\text { Colbert et al. (2016), Mumford et al. (2017), Phelps (2014), Sousa } \\
\text { and Rocha (2019) }\end{array}$ \\
\hline Organisation skills & Giles (2016), Klus and Müller (2020), Phelps (2014) \\
\hline Self-organisation skills & Haromszeki and Jarco (2017), Klus and Müller (2020) \\
\hline Self-reflection skills & $\begin{array}{l}\text { Brown and Posner (2001), Iordanoglou (2018), Klus and Müller } \\
\text { (2020), Reichard and Johnson (2011), Sparrowe (2005) }\end{array}$ \\
\hline Technical skills & Kane et al. (2019), Schwarzmüller et al. (2018) \\
\hline \multicolumn{2}{|l|}{ Traits } \\
\hline Calmness, composure & $\begin{array}{l}\text { Klus and Müller (2020), Ruderman et al. (2001), Seijts and Gandz } \\
\text { (2018) }\end{array}$ \\
\hline Commitment & Drath et al. (2008), Klus and Müller (2020) \\
\hline Courage & $\begin{array}{l}\text { Crossan et al. (2017), Klus and Müller (2020), Seijts and Gandz } \\
\text { (2018) }\end{array}$ \\
\hline Creativity & $\begin{array}{l}\text { Iordanoglou (2018), Klus and Müller (2020), Mumford et al. } \\
\text { (2017), Reiter-Palmon and Illies (2004), Sternberg (2017) }\end{array}$ \\
\hline Empathy & $\begin{array}{l}\text { Holt and Marques (2012), Iordanoglou (2018), Klus and Müller } \\
\text { (2020), Mahsud et al. (2010) }\end{array}$ \\
\hline Flexibility & $\begin{array}{l}\text { Iordanoglou (2018), Klus and Müller (2020), Phelps (2014), } \\
\text { Reiter-Palmon (2003), Yukl and Mahsud (2010) }\end{array}$ \\
\hline Goal orientation & $\begin{array}{l}\text { DeGeest and Brown (2011), Hendricks and Payne (2007), } \\
\text { Iordanoglou (2018), Klus and Müller (2020) }\end{array}$ \\
\hline Independence & Klus and Müller (2020) \\
\hline Openness towards the new & Giles (2016) \\
\hline Willingness to change & Sousa and Rocha (2019) \\
\hline \multicolumn{2}{|l|}{ Challenges } \\
\hline Balancing change & Colbert et al. (2016) \\
\hline Data privacy & Abowd et al. (2019), Zhang (2018) \\
\hline Dealing with many topics & Klus and Müller (2020) \\
\hline Information overload & Klus and Müller (2020), Schwarzmüller et al. (2018) \\
\hline IT aversion of employees & Dimitrov (2018) \\
\hline IT security & Kappelman et al. (2013) \\
\hline Pace of change & $\begin{array}{l}\text { Gordon and Martin 2019, Kane et al. (2019), Klus and Müller } \\
\text { (2020), Kohnke (2017), Schwarzmüller et al. (2018) }\end{array}$ \\
\hline Permanent availability & $\begin{array}{l}\text { Barley et al. (2011), Golden and Geisler (2007), Kane et al. } \\
\text { (2019), Schwarzmüller et al. (2018) }\end{array}$ \\
\hline Personnel development & $\begin{array}{l}\text { Kohnke (2017), Schwarzmüller et al. (2018), Sousa and Rocha } \\
\text { (2019) }\end{array}$ \\
\hline Remote leadership & Colbert et al. (2016), Kane et al. (2019), Klus and Müller (2020) \\
\hline Uncertainty of employees & Schwarzmüller et al. (2018) \\
\hline
\end{tabular}




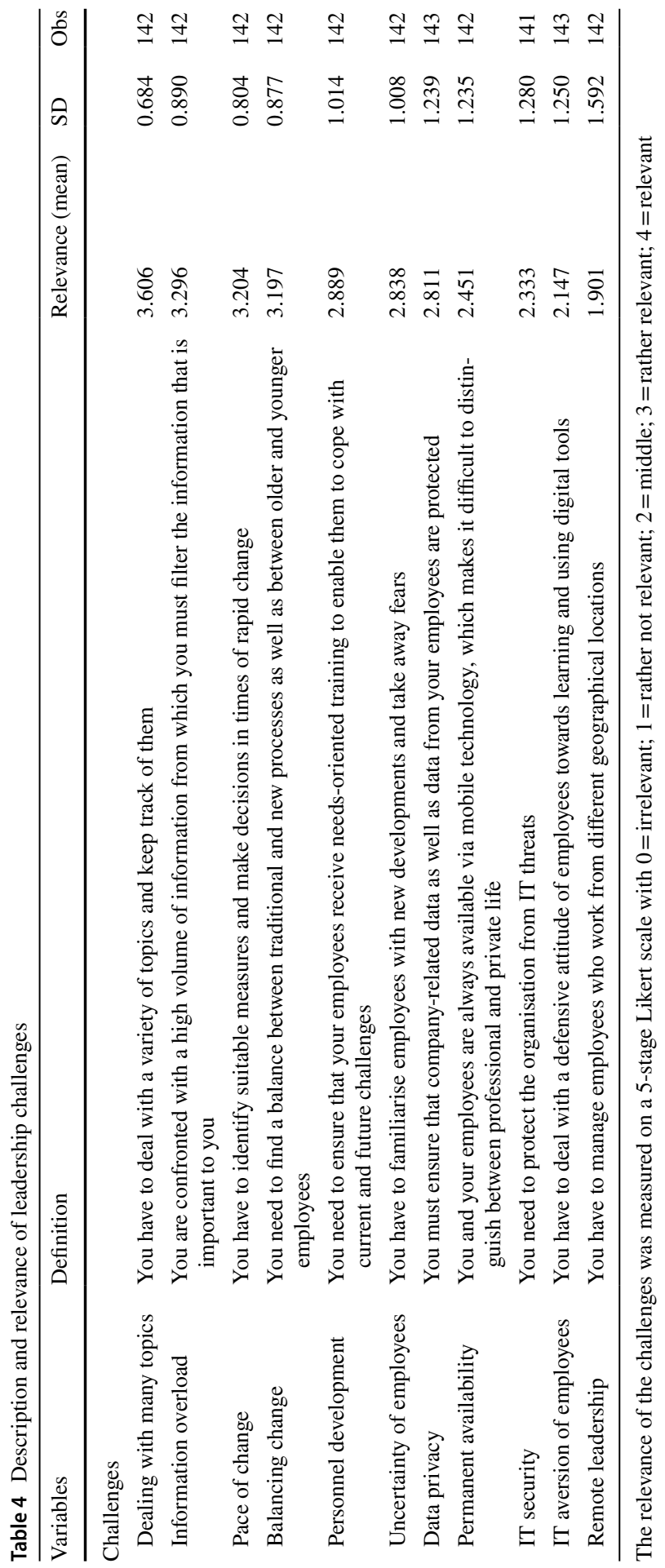




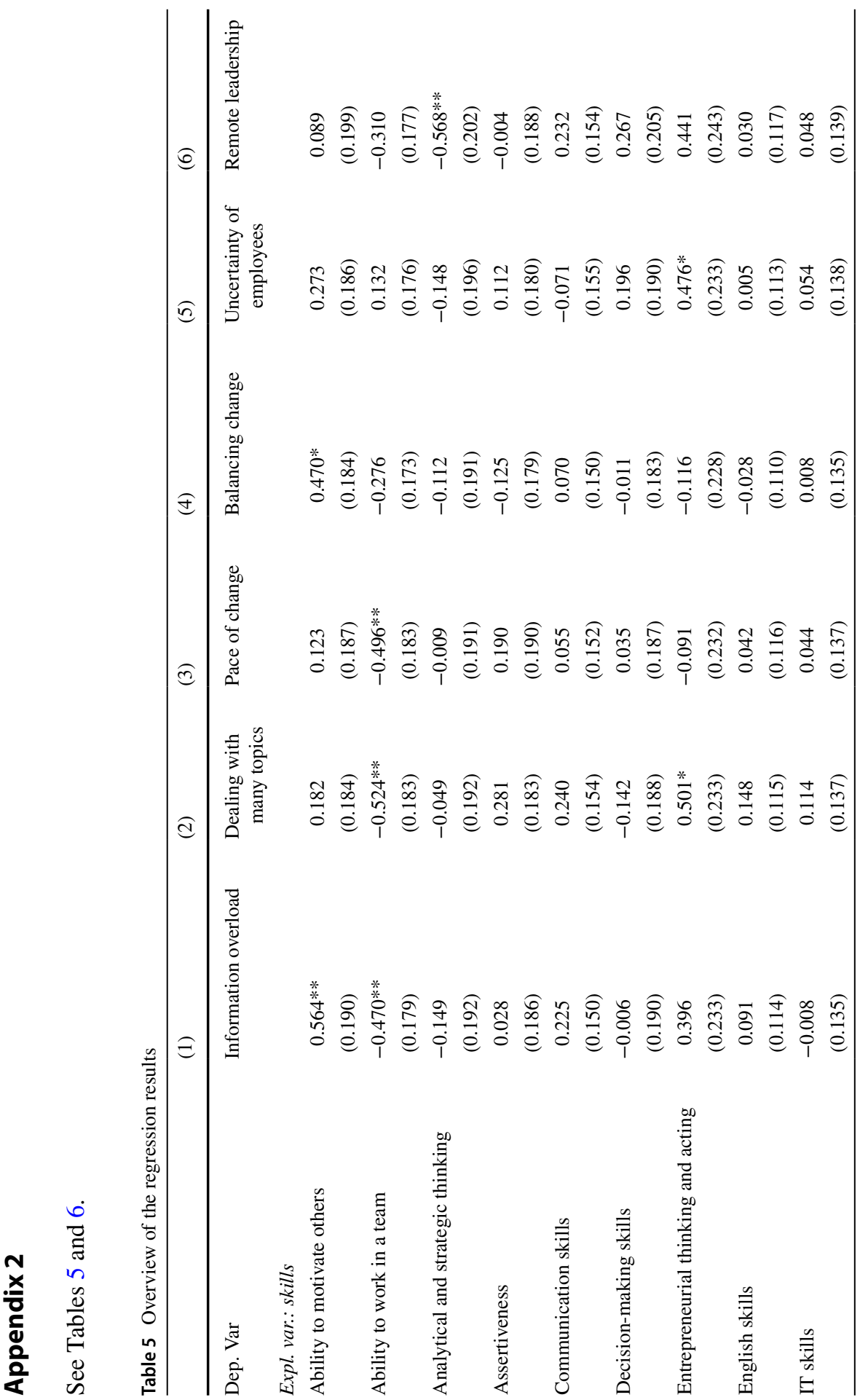




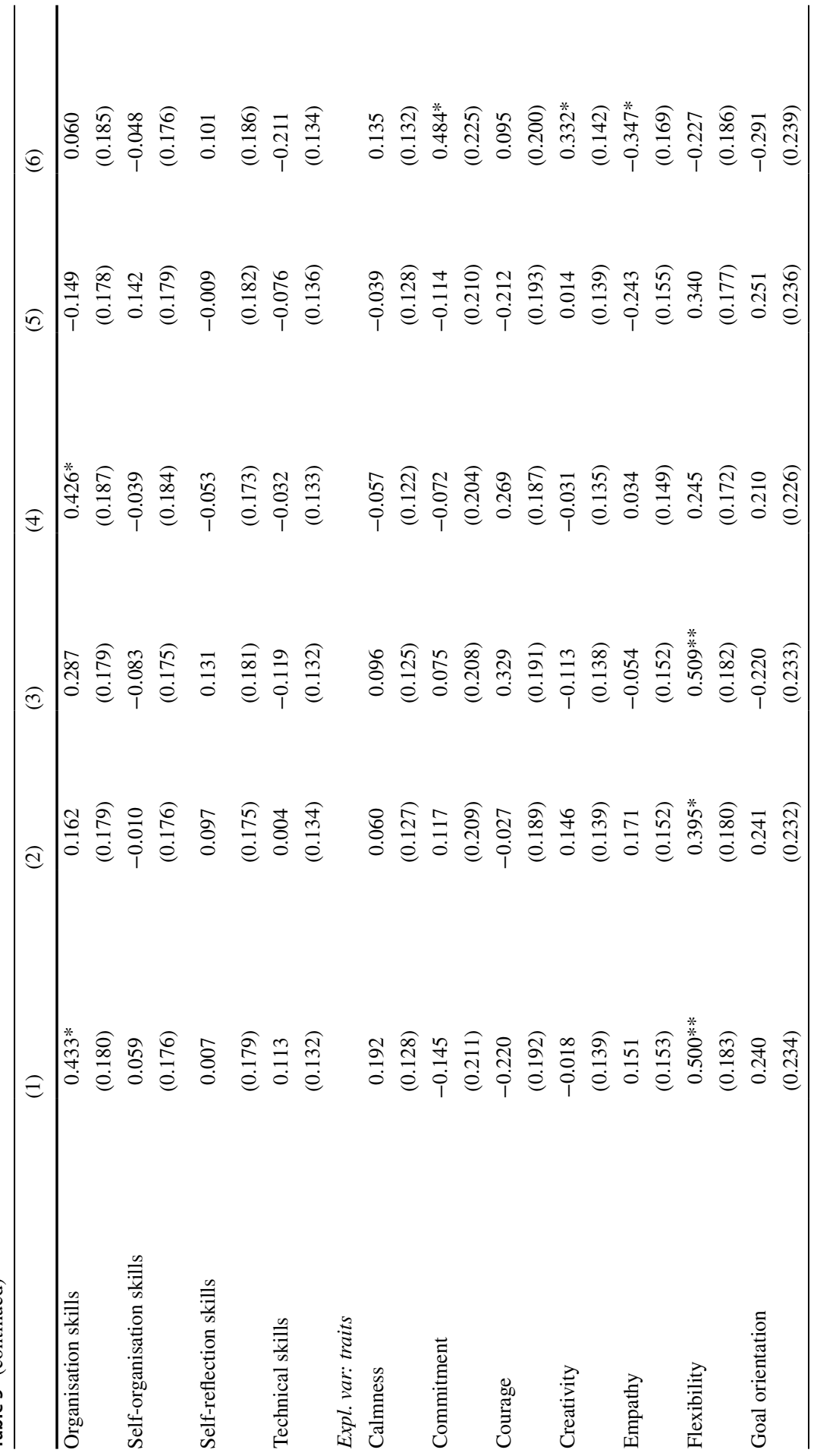




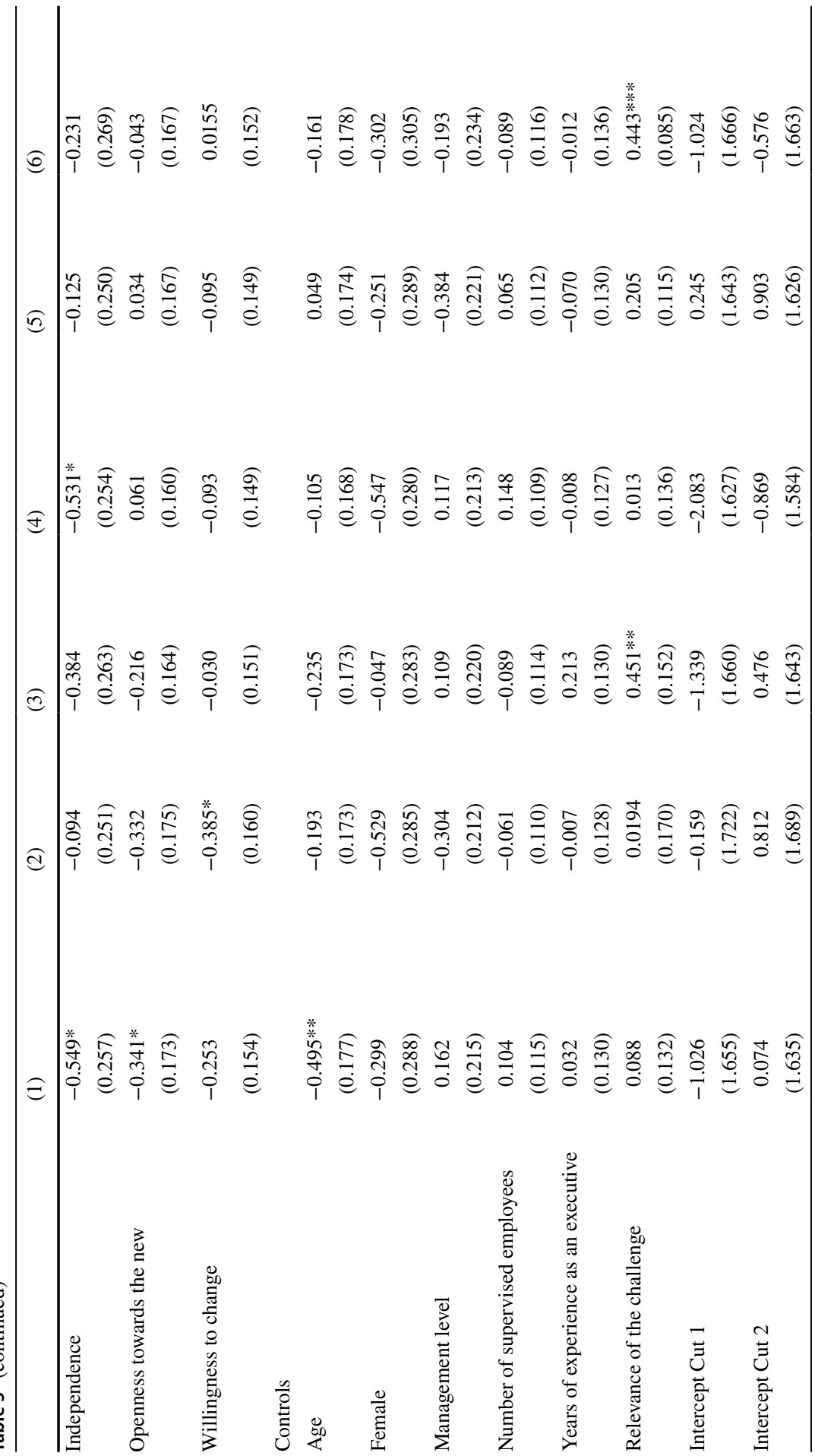




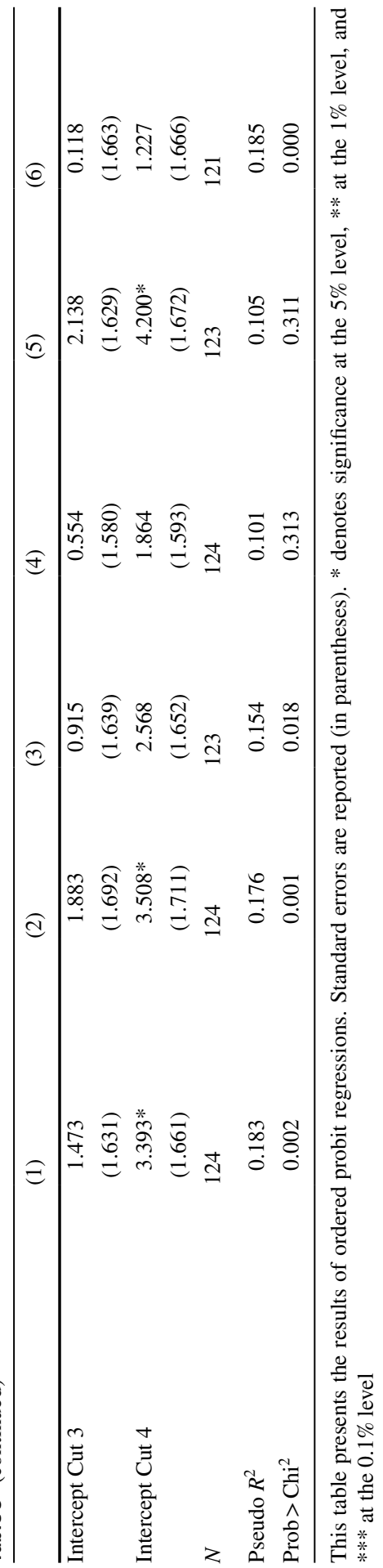


Table 6 Overview of the regression results

\begin{tabular}{|c|c|c|c|c|c|}
\hline & (7) & (8) & (9) & $(10)$ & (11) \\
\hline Dependent variables & IT security & Data privacy & Permanent availability & $\begin{array}{l}\text { IT aversity } \\
\text { of employ- } \\
\text { ees }\end{array}$ & $\begin{array}{c}\text { Personnel } \\
\text { develop- } \\
\text { ment }\end{array}$ \\
\hline \multicolumn{6}{|l|}{ Expl. var.: skills } \\
\hline $\begin{array}{l}\text { Ability to motivate } \\
\text { others }\end{array}$ & $\begin{array}{r}-0.171 \\
(0.182)\end{array}$ & $\begin{array}{c}0.117 \\
(0.178)\end{array}$ & $\begin{array}{c}0.180 \\
(0.185)\end{array}$ & $\begin{array}{r}-0.305 \\
(0.182)\end{array}$ & $\begin{array}{r}0.0803 \\
(0.183)\end{array}$ \\
\hline $\begin{array}{l}\text { Ability to work in a } \\
\text { team }\end{array}$ & $\begin{array}{c}-0.404 * \\
(0.176)\end{array}$ & $\begin{array}{r}-0.246 \\
(0.170)\end{array}$ & $\begin{array}{r}-0.205 \\
(0.172)\end{array}$ & $\begin{array}{r}-0.184 \\
(0.172)\end{array}$ & $\begin{array}{r}-0.129 \\
(0.176)\end{array}$ \\
\hline $\begin{array}{l}\text { Analytical and strategic } \\
\text { thinking }\end{array}$ & $\begin{array}{c}-0.484^{*} \\
(0.197)\end{array}$ & $\begin{array}{l}-0.164 \\
(0.187)\end{array}$ & $\begin{array}{c}-0.380^{*} \\
(0.190)\end{array}$ & $\begin{array}{c}-0.0560 \\
(0.186)\end{array}$ & $\begin{array}{r}0.0488 \\
(0.195)\end{array}$ \\
\hline Assertiveness & $\begin{array}{c}0.257 \\
(0.181)\end{array}$ & $\begin{array}{c}0.080 \\
(0.178)\end{array}$ & $\begin{array}{c}0.223 \\
(0.186)\end{array}$ & $\begin{array}{c}0.213 \\
(0.182)\end{array}$ & $\begin{array}{r}0.0207 \\
(0.182)\end{array}$ \\
\hline Communication skills & $\begin{array}{c}0.035 \\
(0.144)\end{array}$ & $\begin{array}{c}0.133 \\
(0.144)\end{array}$ & $\begin{array}{r}-0.003 \\
(0.148)\end{array}$ & $\begin{array}{r}0.0148 \\
(0.148)\end{array}$ & $\begin{array}{c}0.113 \\
(0.151)\end{array}$ \\
\hline Decision making skills & $\begin{array}{c}0.269 \\
(0.183)\end{array}$ & $\begin{array}{c}0.092 \\
(0.181)\end{array}$ & $\begin{array}{r}-0.316 \\
(0.188)\end{array}$ & $\begin{array}{r}-0.214 \\
(0.185)\end{array}$ & $\begin{array}{r}-0.274 \\
(0.189)\end{array}$ \\
\hline $\begin{array}{l}\text { Entrepreneurial thinking } \\
\text { and acting }\end{array}$ & $\begin{array}{c}0.045 \\
(0.225)\end{array}$ & $\begin{array}{c}0.053 \\
(0.224)\end{array}$ & $\begin{array}{c}0.174 \\
(0.223)\end{array}$ & $\begin{array}{c}0.288 \\
(0.225)\end{array}$ & $\begin{array}{c}0.171 \\
(0.228)\end{array}$ \\
\hline English skills & $\begin{array}{c}0.168 \\
(0.110)\end{array}$ & $\begin{array}{c}0.0161 \\
(0.110)\end{array}$ & $\begin{array}{c}0.209 \\
(0.112)\end{array}$ & $\begin{array}{r}-0.107 \\
(0.110)\end{array}$ & $\begin{array}{c}0.101 \\
(0.111)\end{array}$ \\
\hline IT skills & $\begin{array}{l}0.372 * * \\
(0.137)\end{array}$ & $\begin{array}{c}0.268^{*} \\
(0.134)\end{array}$ & $\begin{array}{c}0.106 \\
(0.131)\end{array}$ & $\begin{array}{l}0.407 * * \\
(0.136)\end{array}$ & $\begin{array}{c}0.298 * \\
(0.136)\end{array}$ \\
\hline Organisation skills & $\begin{array}{r}-0.158 \\
(0.176)\end{array}$ & $\begin{array}{r}-0.067 \\
(0.173)\end{array}$ & $\begin{array}{r}-0.116 \\
(0.177)\end{array}$ & $\begin{array}{c}0.0839 \\
(0.174)\end{array}$ & $\begin{array}{c}0.0901 \\
(0.181)\end{array}$ \\
\hline Self-organisation skills & $\begin{array}{c}0.160 \\
(0.175)\end{array}$ & $\begin{array}{l}0.482^{* *} \\
(0.173)\end{array}$ & $\begin{array}{l}0.564 * * \\
(0.180)\end{array}$ & $\begin{array}{c}-0.0441 \\
(0.170)\end{array}$ & $\begin{array}{c}0.177 \\
(0.175)\end{array}$ \\
\hline Self reflection skills & $\begin{array}{c}0.146 \\
(0.171)\end{array}$ & $\begin{array}{r}-0.133 \\
(0.171)\end{array}$ & $\begin{array}{r}-0.187 \\
(0.172)\end{array}$ & $\begin{array}{c}-0.0309 \\
(0.171)\end{array}$ & $\begin{array}{c}0.0718 \\
(0.174)\end{array}$ \\
\hline Technical skills & $\begin{array}{c}0.114 \\
(0.132)\end{array}$ & $\begin{array}{c}0.334 * \\
(0.131)\end{array}$ & $\begin{array}{c}0.188 \\
(0.131)\end{array}$ & $\begin{array}{l}0.00787 \\
(0.130)\end{array}$ & $\begin{array}{r}-0.139 \\
(0.131)\end{array}$ \\
\hline \multicolumn{6}{|l|}{ Expl. var.: traits } \\
\hline Calmness & $\begin{array}{c}0.052 \\
(0.125)\end{array}$ & $\begin{array}{c}0.037 \\
(0.122)\end{array}$ & $\begin{array}{c}0.218 \\
(0.126)\end{array}$ & $\begin{array}{c}0.0184 \\
(0.123)\end{array}$ & $\begin{array}{c}-0.0758 \\
(0.125)\end{array}$ \\
\hline Commitment & $\begin{array}{l}0.609 * * \\
(0.213)\end{array}$ & $\begin{array}{l}0.630 * * \\
(0.206)\end{array}$ & $\begin{array}{c}0.148 \\
(0.210)\end{array}$ & $\begin{array}{c}0.545^{*} \\
(0.213)\end{array}$ & $\begin{array}{c}0.376 \\
(0.209)\end{array}$ \\
\hline Courage & $\begin{array}{c}0.119 \\
(0.186)\end{array}$ & $\begin{array}{c}0.186 \\
(0.183)\end{array}$ & $\begin{array}{r}-0.287 \\
(0.185)\end{array}$ & $\begin{array}{c}0.271 \\
(0.186)\end{array}$ & $\begin{array}{c}0.204 \\
(0.188)\end{array}$ \\
\hline Creativity & $\begin{array}{l}0.421 * * \\
(0.138)\end{array}$ & $\begin{array}{r}-0.091 \\
(0.133)\end{array}$ & $\begin{array}{c}0.192 \\
(0.136)\end{array}$ & $\begin{array}{c}0.143 \\
(0.136)\end{array}$ & $\begin{array}{c}0.0547 \\
(0.138)\end{array}$ \\
\hline Empathy & $\begin{array}{c}0.185 \\
(0.149)\end{array}$ & $\begin{array}{c}0.206 \\
(0.149)\end{array}$ & $\begin{array}{r}-0.049 \\
(0.147)\end{array}$ & $\begin{array}{c}0.0386 \\
(0.148)\end{array}$ & $\begin{array}{c}0.234 \\
(0.154)\end{array}$ \\
\hline Flexibility & $\begin{array}{c}0.032 \\
(0.175)\end{array}$ & $\begin{array}{r}-0.087 \\
(0.169)\end{array}$ & $\begin{array}{c}0.208 \\
(0.177)\end{array}$ & $\begin{array}{c}0.145 \\
(0.170)\end{array}$ & $\begin{array}{c}0.204 \\
(0.173)\end{array}$ \\
\hline
\end{tabular}


Table 6 (continued)

\begin{tabular}{|c|c|c|c|c|c|}
\hline & (7) & (8) & (9) & $(10)$ & (11) \\
\hline \multirow[t]{2}{*}{ Goal orientation } & -0.201 & -0.396 & -0.012 & -0.381 & 0.221 \\
\hline & $(0.229)$ & $(0.224)$ & $(0.228)$ & $(0.225)$ & $(0.228)$ \\
\hline \multirow[t]{2}{*}{ Independence } & -0.228 & 0.129 & -0.091 & -0.210 & -0.298 \\
\hline & $(0.255)$ & $(0.244)$ & $(0.248)$ & $(0.248)$ & $(0.248)$ \\
\hline \multirow{2}{*}{$\begin{array}{l}\text { Openness towards the } \\
\text { new }\end{array}$} & -0.058 & 0.009 & -0.146 & 0.267 & 0.144 \\
\hline & $(0.158)$ & $(0.158)$ & $(0.159)$ & $(0.162)$ & $(0.162)$ \\
\hline \multirow[t]{2}{*}{ Willingness to change } & $-0.315^{*}$ & 0.003 & -0.245 & -0.0394 & 0.124 \\
\hline & $(0.154)$ & $(0.147)$ & $(0.150)$ & $(0.148)$ & $(0.148)$ \\
\hline \multicolumn{6}{|l|}{ Controls } \\
\hline \multirow[t]{2}{*}{ Age } & -0.063 & -0.085 & $-0.350 *$ & 0.0426 & $-0.342 *$ \\
\hline & $(0.169)$ & $(0.173)$ & $(0.172)$ & $(0.169)$ & $(0.173)$ \\
\hline \multirow[t]{2}{*}{ Female } & $-0.651^{*}$ & -0.320 & $-0.622 *$ & $-0.629 *$ & -0.310 \\
\hline & $(0.283)$ & $(0.275)$ & $(0.278)$ & $(0.282)$ & $(0.283)$ \\
\hline \multirow[t]{2}{*}{ Management level } & 0.055 & 0.004 & $-1.077 * * *$ & -0.150 & 0.294 \\
\hline & $(0.217)$ & $(0.207)$ & $(0.220)$ & $(0.209)$ & $(0.220)$ \\
\hline \multirow{2}{*}{$\begin{array}{l}\text { Number of supervised } \\
\text { employees }\end{array}$} & -0.043 & -0.022 & -0.206 & 0.0821 & 0.0356 \\
\hline & $(0.107)$ & $(0.107)$ & $(0.110)$ & $(0.107)$ & $(0.108)$ \\
\hline \multirow{2}{*}{$\begin{array}{l}\text { Years of experience as } \\
\text { an executive }\end{array}$} & -0.038 & 0.080 & 0.0607 & -0.0185 & 0.207 \\
\hline & $(0.124)$ & $(0.125)$ & $(0.126)$ & $(0.126)$ & $(0.128)$ \\
\hline \multirow{2}{*}{$\begin{array}{l}\text { Relevance of the chal- } \\
\text { lenge }\end{array}$} & 0.039 & 0.098 & 0.123 & -0.147 & $0.389 * *$ \\
\hline & $(0.091)$ & $(0.091)$ & $(0.0985)$ & $(0.0887)$ & $(0.134)$ \\
\hline \multirow[t]{2}{*}{ Intercept Cut 1} & 0.751 & $3.043^{*}$ & $-4.479 * *$ & 0.109 & $4.146^{*}$ \\
\hline & $(1.525)$ & $(1.552)$ & $(1.582)$ & $(1.542)$ & (1.619) \\
\hline \multirow[t]{2}{*}{ Intercept Cut 2} & 1.428 & $4.082 * *$ & $-3.677^{*}$ & 0.931 & $5.281 * *$ \\
\hline & $(1.527)$ & $(1.551)$ & $(1.581)$ & $(1.538)$ & $(1.615)$ \\
\hline \multirow[t]{2}{*}{ Intercept Cut 3} & 2.662 & $5.057 * *$ & -2.634 & 2.459 & $6.729 * * *$ \\
\hline & $(1.533)$ & $(1.563)$ & $(1.573)$ & (1.549) & $(1.641)$ \\
\hline \multirow[t]{2}{*}{ Intercept Cut 4} & $3.571 *$ & $6.558 * * *$ & -1.317 & $3.379 *$ & $8.322 * * *$ \\
\hline & $(1.545)$ & $(1.606)$ & $(1.554)$ & $(1.558)$ & $(1.694)$ \\
\hline$N$ & 122 & 124 & 124 & 124 & 124 \\
\hline Pseudo $R^{2}$ & 0.136 & 0.128 & 0.176 & 0.139 & 0.178 \\
\hline Prob $>\mathrm{Chi}^{2}$ & 0.008 & 0.024 & 0.000 & 0.012 & 0.001 \\
\hline
\end{tabular}

This table presents the results of ordered probit regressions. Standard errors are reported (in parentheses). $*$ denotes significance at the $5 \%$ level, $* *$ at the $1 \%$ level, and *** at the $0.1 \%$ level

Funding Open Access funding enabled and organized by Projekt DEAL.

Open Access This article is licensed under a Creative Commons Attribution 4.0 International License, which permits use, sharing, adaptation, distribution and reproduction in any medium or format, as long as you give appropriate credit to the original author(s) and the source, provide a link to the Creative 
Commons licence, and indicate if changes were made. The images or other third party material in this article are included in the article's Creative Commons licence, unless indicated otherwise in a credit line to the material. If material is not included in the article's Creative Commons licence and your intended use is not permitted by statutory regulation or exceeds the permitted use, you will need to obtain permission directly from the copyright holder. To view a copy of this licence, visit http://creativecommons.org/ licenses/by/4.0/.

\section{References}

Abowd JM, Schmutte IM, Sexton WN, Vilhuber L (2019) Why the economics profession must actively participate in the privacy protection debate. AEA Pap Proc 109:397-402

Ahlquist J (2014) Trending now: digital leadership education using social media and the social change model. J Leadersh Stud 8(2):57-60

Ames DR (2009) Pushing up to a point: assertiveness and effectiveness in leadership and interpersonal dynamics. Res Organ Behav 29:111-133

Ames DR, Flynn FJ (2007) What breaks a leader: the curvilinear relation between assertiveness and leadership. J Pers Soc Psychol 92(2):307-324

Autor DH (2015) Why are there still so many jobs? The history and future of workplace automation. J Econ Perspect 29(3):3-30

Avolio J, Kahai S (2003) Adding the "E" to E-leadership: how it may impact your leadership. Organ Dyn 31(4):325-338

Avolio BJ, Kahai S, Dodge GE (2000) E-leadership: implications for theory, research, and practice. Leadersh Q 11(4):615-668

Bacon CC, Severson ML (1986) Assertiveness, responsiveness, and versatility as predictors of leadership emergence. Commun Res Rep 3(1):53-59

Barley SR, Meyerson DE, Grodal S (2011) E-mail as a source and symbol of stress. Organ Sci 22(4):887-906

Bondarouk T, Ruël HJM (2009) Electronic human resource management: challenges in the digital era. Int J Hum Resour Manag 20(3):505-514

Brown LM, Posner BZ (2001) Exploring the relationship between learning and leadership. Leadersh Organ Dev J 22(6):274-280

Buengeler C, Homan AC, Voelpel SC (2016) The challenge of being a young manager: the effects of contingent reward and participative leadership on team-level turnover depend on leader age. J Organ Behav 37(8):1224-1245

Cable DM, Judge TA (2003) Managers' upward influence tactic strategies: the role of manager personality and supervisor leadership style. J Organ Behav 24(2):197-214

Cascio WF, Shurygailo S (2003) E-leadership and virtual teams. Organ Dyn 31(4):362-376

Colbert A, Yee N, George G (2016) The digital workforce and the workplace of the future. Acad Manag J 59(3):731-739

Creţu D, Iova RA (2015) Identification of leadership skills and behaviours, in the business sector. Case study. Proc Soc Behav Sci 186:526-534

Crossan MM, Byrne A, Seijts GH, Reno M, Monzani L, Gandz J (2017) Toward a framework of leader character in organizations. J Manag Stud 54(7):986-1018

Day DV, Fleenor JW, Atwater LE, Sturm RE, McKee RA (2014) Advances in leader and leadership development: a review of 25 years of research and theory. Leadersh Q 25(1):63-82

DeGeest D, Brown KG (2011) The role of goal orientation in leadership development. Hum Resour Dev Q 22(2):157-175

Dimitrov A (2018) The digital age leadership: a transhumanistic perspective. J Leadersh Stud 12(3):79-81

Drath WH, McCauley CD, Palus CJ, Van Velsor E, O’Connor PMG, McGuire JB (2008) Direction, alignment, commitment: toward a more integrative ontology of leadership. Leadersh Q 19(6):635-653

El Sawy OA, Kræmmergaard P, Amsinck H, Vinther AL (2016) How LEGO built the foundations and enterprise capabilities for digital leadership. MIS Q Exec 15(2):141-166

Franklin S, Walker C (2003) Survey methods and practices. Statistics Canada, Ottawa

Furnari S, Crilly D, Misangyi VF, Greckhamer T, Fiss P, Aguilera R (2020) Capturing causal complexity: heuristics for configurational theorizing. Acad Manage REV (forthcoming)

George G, Haas MR, Pentland A (2014) Big data and management. Acad Manag J 57(2):321-326 
George G, Osinga EC, Lavie D, Scott BA (2016) Big data and data science methods for management research. Acad Manag J 59(5):1493-1507

Giles S (2016) The most important leadership competencies, according to leaders around the world. Harvard Business Review. https://hbr.org/2016/03/the-most-important-leadership-competencies-accor ding-to-leaders-around-the-world?autocomplete=true. Accessed 25 November 2019

Gioia DA, Corley KG, Hamilton AL (2013) Seeking qualitative rigor in inductive research: notes on the Gioia methodology. Organ Res Methods 16(1):15-31

Golden AG, Geisler C (2007) Work-life boundary management and the personal digital assistant. Hum Relat 60(3):519-551

Gordon V, Martin D (2019) The 21st-century CEO: Intrinsic attributes, worldview, and communication capabilities. J Leadersh Organ Stud 26(2):141-149

Gratton L (2016) Rethinking the manager's role. MIT Sloan Manag Rev 58(1):24-27

Grijalva E, Harms PD, Newman DA, Gaddis BH, Fraley RC (2015) Narcissism and leadership: a metaanalytic review of linear and nonlinear relationships. Pers Psychol 68(1):1-47

Guillén L, Mayo M, Korotov K (2015) Is leadership a part of me? A leader identity approach to understanding the motivation to lead. Leadersh Q 26(5):802-820

Hambley LA, O’Neill TA, Kline TJ (2007) Virtual team leadership: the effects of leadership style and communication medium on team interaction styles and outcomes. Organ Behav Hum Decis Process 103(1):1-20

Haromszeki Ł, Jarco P (2017) Educational leaders and their qualities from the 'followers' perspective. J Intercult Manag 9(4):77-96

Haycock K, Cheadle A, Bluestone KS (2012) Strategic thinking-lessons for leadership from the literature. Libr Leadersh Manag 26(3/4):1-23

Hendricks JW, Payne SC (2007) Beyond the big five: leader goal orientation as a predictor of leadership effectiveness. Hum Performa 20(4):317-343

Holt S, Marques J (2012) Empathy in leadership: appropriate or misplaced? An empirical study on a topic that is asking for attention. J Bus Ethics 105(1):95-105

Hunt CS (2015) Leading in the digital era. Talent Dev 69(6):48-53

Iordanoglou D (2018) Future trends in leadership development practices and the crucial leadership skills. J Leadersh Account Ethics 15(2):118-129

Kane GC, Phillips AN, Copulsky J, Andrus G (2019) How digital leadership is(n't) different: leaders must blend traditional and new skills to effectively guide their organizations into the future. MIT Sloan Manag Rev 60(3):34-39

Kappelman L, McLean E, Luftman J, Johnson V (2013) Key issues of IT organizations and their leadership: the 2013 SIM IT trends study. MIS Q Exec 12(4):227-240

Katz RL (1974) Skills of an effective administrator. Harv Bus Rev 52(5):90-102

Khan A, Ahmad W (2012) Leader's interpersonal skills and its effectiveness at different levels of management. Int J Bus Soc Sci 3(4):296-305

Kitchin R (2014) Big data, new epistemologies and paradigm shifts. Big Data Soc 1(1):1-12

Klus MF, Müller J (2020) Identifying leadership skills required in the digital age. CESifo Working Paper No. 8180:1-35

Kohnke O (2017) It's not just about technology: The people side of digitization. In: Oswald G, Kleinemeir M (eds) Shaping the digital enterprise. Springer, Berlin, pp 69-91

Kuratko DF, Hornsby JS (1999) Corporate entrepreneurial leadership for the 21 st century. J Leadersh Stud 5(2):27-39

Likert R (1974) A method of constructing an attitude scale. In: Maranell G (ed) Scaling: a sourcebook for behavioral scientists. Aldine Pub, Chicago, pp 233-243

Lord RG, Hall RJ (2005) Identity, deep structure and the development of leadership skill. Leadersh Q 16(4):591-615

Maccoby M (2000) Narcissistic leaders. Harv Bus Rev 78(1):69-77

Mahsud R, Yukl G, Prussia G (2010) Leader empathy, ethical leadership, and relations-oriented behaviors as antecedents of leader-member exchange quality. J Manag Psychol 25(6):561-577

Marler JH, Parry E (2016) Human resource management, strategic involvement and e-HRM technology. Int J Hum Resour Manag 27(19):2233-2253

Mumford TV, Campion MA, Morgeson FP (2007) The leadership skills strataplex: leadership skill requirements across organizational levels. Leadersh Q 18(2):154-166

Mumford MD, Todd EM, Higgs C, McIntosh T (2017) Cognitive skills and leadership performance: the nine critical skills. Leadersh Q 28(1):24-39 
Nurmi R (1996) Teamwork and team leadership. Team Perform Manag 2(1):9-13

Osburg T, Lohrmann C (2017) Sustainability in a digital world. Springer, Cham

Phelps KC (2014) "So much technology, so little talent"? Skills for harnessing technology for leadership outcomes. J Leadersh Stud 8(2):51-56

Pulley ML, Sessa VI (2001) E-leadership: tackling complex challenges. Ind Commerc Train 33(6):225-229

Reichard RJ, Johnson SK (2011) Leader self-development as organizational strategy. Leadersh Q 22(1):33-42

Reiter-Palmon R (2003) Predicting leadership activities: the role of flexibility. Individ Differ Res 1(2):124

Reiter-Palmon R, Illies JJ (2004) Leadership and creativity: understanding leadership from a creative problem-solving perspective. Leadersh Q 15(1):55-77

Roy SR (2012) Digital mastery: The skills needed for effective virtual leadership. Int J e-Collab $8(3): 56-66$

Ruderman MN, Hannum K, Leslie J, Steed J (2001) Leadership skills and emotional intelligence. Center for Creative Leadership, Greensboro

Ruël HJM, Bondarouk T, Looise JK (2004) E-HRM: innovation or irritation. An explorative empirical study in five large companies on web-based HRM. Manag Rev 15(3):364-380

Ruël HJM, Bondarouk T, Van der Velde M (2007) The contribution of e-HRM to HRM effectiveness: results from a quantitative study in a Dutch ministry. Empl Relat 29(3):280-291

Santora JC (2007) Assertiveness and effective leadership: is there a tipping point? Acad Manag Perspecti 21(3):84-86

Savolainen T (2014) Trust-building in e-leadership: a case study of leaders' challenges and skills in technology-mediated interaction. J Glob Bus Issues 8(2):45-56

Schwarzmüller T, Brosi P, Duman D, Welpe IM (2018) How does the digital transformation affect organizations? Key themes of change in work design and leadership. Manag Rev 29(2):114-138

Seijts GH, Gandz J (2018) Transformational change and leader character. Bus Horiz 61(2):239-249

Sheninger E (2019) Digital leadership: changing paradigms for changing times. Corwin Press, Thousand Oaks

Sousa MJ, Rocha Á (2019) Skills for disruptive digital business. J Bus Res 94:257-263

Sparrowe RT (2005) Authentic leadership and the narrative self. Leadersh Q 16(3):419-439

Sternberg RJ (2017) Developing the next generation of responsible professionals: wisdom and ethics trump knowledge and IQ. Psychol Teach Rev 23(2):51-59

Strohmeier S (2007) Research in e-HRM: review and implications. Hum Resour Manag Rev 17(1):19-37

Tarafdar M (2016) The three new skills managers need. MIT Sloan Manag Rev 58(1):162-166

Wilson EJ III (2004) Leadership in the digital age. In: Goethals GR, Sorenson G, MacGregor Burns J (eds) Encyclopedia of leadership, 4th edn. Sage, Thousand Oaks, pp 858-861

Wipulanusat W, Panuwatwanich K, Stewart RA (2017) Exploring leadership styles for innovation: an exploratory factor analysis. Eng Manag Prod Serv 9(1):7-17

Yukl G, Mahsud R (2010) Why flexible and adaptive leadership is essential. Consult Psychol J Pract Res 62(2):81-93

Zeike S, Bradbury K, Lindert L, Pfaff H (2019) Digital leadership skills and associations with psychological well-being. Int J Environ Res Public Health 16(14):1-12

Zhang D (2018) Big data security and privacy protection. Adv Comput Sci Res 77:275-278

Publisher's Note Springer Nature remains neutral with regard to jurisdictional claims in published maps and institutional affiliations. 